\title{
A dynamic marine iron cycle module coupled to the University of Victoria Earth System Model: the Kiel Marine Biogeochemical Model 2 for UVic 2.9
}

\author{
L. Nickelsen, D. P. Keller, and A. Oschlies \\ GEOMAR Helmholtz-Zentrum für Ozeanforschung Kiel, Düsternbrooker Weg 20, 24105 Kiel, Germany \\ Correspondence to: L. Nickelsen (lnickelsen@geomar.de)
}

Received: 15 October 2014 - Published in Geosci. Model Dev. Discuss.: 5 December 2014

Revised: 5 March 2015 - Accepted: 19 April 2015 - Published: 12 May 2015

\begin{abstract}
Marine biological production as well as the associated biotic uptake of carbon in many ocean regions depends on the availability of nutrients in the euphotic zone. While large areas are limited by nitrogen and/or phosphorus, the micronutrient iron is considered the main limiting nutrient in the North Pacific, equatorial Pacific and Southern Ocean. Changes in iron availability via changes in atmospheric dust input are discussed to play an important role in glacial-interglacial cycles via climate feedbacks caused by changes in biological ocean carbon sequestration. Although many aspects of the iron cycle remain unknown, its incorporation into marine biogeochemical models is needed to test our current understanding and better constrain its role in the Earth system. In the University of Victoria Earth System Climate Model (UVic) iron limitation in the ocean was, until now, simulated pragmatically with an iron concentration masking scheme that did not allow a consistent interactive response to perturbations of ocean biogeochemistry or iron cycling sensitivity studies. Here, we replace the iron masking scheme with a dynamic iron cycle and compare the results to available observations and the previous marine biogeochemical model. Sensitivity studies are also conducted with the new model to test the sensitivity of the model to parameterized iron ligand concentrations, the importance of considering the variable solubility of iron in dust deposition, the importance of considering high-resolution bathymetry for the sediment release of iron, the effect of scaling the sedimentary iron release with temperature and the sensitivity of the iron cycle to a climate change scenario.
\end{abstract}

\section{Introduction}

The Earth system consists of three major components: ocean, atmosphere and land. All of them interact and shape the Earth's climate. Understanding the most important dynamics and the way they influence the climate is an urgent task because of mankind's dependence on, and increasing interference with, the climate of our planet. The ocean is a particularly important component of the Earth system since it has the capacity to compensate for large fluctuations of the greenhouse gas $\mathrm{CO}_{2}$ in the atmosphere. For instance, Sabine et al. (2004) estimated that the global oceanic anthropogenic $\mathrm{CO}_{2}$ sink for the period from 1800 to 1994 accounts for $48 \%$ of the total fossil-fuel and cement-manufacturing emissions. The oceanic uptake of anthropogenic carbon is thought to have, until now, occurred predominantly through the solubility pump, which describes the physical dissolution of $\mathrm{CO}_{2}$ in sea water, a strongly temperature-dependent process with more $\mathrm{CO}_{2}$ being absorbed into cold, high latitude waters that sink into the ocean interior. So far, there is little evidence for changes in the so-called biological pump that transfers carbon from the surface ocean via phytoplankton uptake and sinking of organic matter to the deeper ocean. The biological pump does, however, have a huge potential to affect the partitioning of carbon between the ocean and the atmosphere. Its strength in many regions depends on nutrient limitation of phytoplankton so that ocean biogeochemistry has an influence on the global carbon cycle and climate.

Over the last two decades iron has been discovered to play an important role in ocean biogeochemistry. The availability of iron limits phytoplankton growth in the North Pacific, 
equatorial Pacific and Southern Ocean (Boyd and Ellwood, 2010). Dust deposition and more recently sediment release of iron are seen as the major sources of iron to the ocean. Increases in Southern Ocean dust deposition are still discussed as possibly contributing to glacial-interglacial changes in atmospheric $\mathrm{CO}_{2}$ concentrations by reducing Southern Ocean iron limitation (Martinez-Garcia et al., 2014). On the other hand, Tagliabue et al. (2014a) found in a modeling study that without sediment release of iron, the atmospheric $\mathrm{CO}_{2}$ concentration would be 10.0-18.2 ppm higher. Furthermore, iron is particularly important for nitrogen fixing phytoplankton, so-called diazotrophs that have a strong impact on the balance of the ocean nitrogen inventory (Mills et al., 2004; Moore and Doney, 2007; Somes et al., 2010). Thus, the marine iron cycle is an important part of the Earth system.

Earth system models are well suited for investigating the dynamics and sensitivities of the earth system to perturbations. However, Earth system and global ocean-only models have usually incorporated representations of the iron cycle with a varying degree of complexity (Moore and Braucher, 2008; Parekh et al., 2008; Tagliabue et al., 2014a). A low level of complexity is useful for example, for investigating the sensitivity of oceanic $\mathrm{CO}_{2}$ uptake to dust deposition or for comparing the role of sedimentary iron release to that of aeolian iron deposition. However, these models can have quite different sensitivities and a comparison of the models and their assumptions can indicate the reasons for the different sensitivities (Tagliabue et al., 2008). More mechanistic models are needed to identify the important processes and their sensitivities to environmental changes, and to reduce uncertainties in the model simulations.

In the University of Victoria Earth System Climate Model (UVic), which we use in this study, iron limitation has either been ignored (Schmittner et al., 2008) or modeled with the use of an iron deposition mask (Somes et al., 2013) and of a non-dynamic iron masking scheme (Keller et al., 2012) that was based on iron concentrations calculated by another model (Galbraith et al., 2010), which contained a dynamic iron cycle. Thus, the iron concentrations in the most recent version of the marine biogeochemical component (Keller et al., 2012) are not interactive with the rest of the model. Furthermore, sensitivity studies and experiments that require dynamic feedbacks of the iron cycle from changes in biogeochemistry and physics cannot be carried out with a constant iron concentration mask. Here, we add a dynamic iron cycle to the UVic marine biogeochemical model to create the ability to investigate the iron cycle itself, the interactions of the iron cycle with other biogeochemical cycles and the climate. Our results indicate the importance of including the variable solubility of dust-deposited iron and the importance of the depth of sedimentary iron release to the water column. We also find that scaling the benthic iron release with temperature increases the agreement between simulated and observed iron concentrations in the Southern Ocean and a high sensitivity of dissolved iron concentrations to parameterized ligand concentrations. The new model allows us to provide an estimate of global marine iron fluxes and shows how implementing the dynamic iron cycle improves the agreement of simulated ocean tracers with observations. Finally, the dynamic response of the iron cycle during a climate change scenario simulation is demonstrated.

\section{Model description}

A dynamic iron cycle is added to the Kiel Marine Biogeochemical Model (KMBM) by Keller et al. (2012) and coupled to the UVic version 2.9 (Eby et al., 2009, 2013; Weaver et al., 2001). The UVic model and the ocean biogeochemical model are briefly outlined before the new dynamic iron cycle is described.

\subsection{The University of Victoria Earth System Climate Model}

The UVic model (Eby et al., 2009, 2013; Weaver et al., 2001) is an Earth system model of intermediate complexity (EMIC) with the advantage of relatively low computational costs. The model consists of three components: a simple one layer atmospheric model, a terrestrial model and a three-dimensional ocean circulation model. The horizontal grid resolution of all model components is $3.6^{\circ}$ in meridional and $1.8^{\circ}$ in latitudinal direction. The atmospheric component is an energymoisture balance model that dynamically calculates heat and water fluxes between the atmosphere and the ocean, land and sea ice. Advection of water vapor in the atmosphere is calculated using monthly climatological wind data from the National Center for Atmospheric Research/National Center for Environmental Prediction (NCAR/NCEP). The land vegetation model is the terrestrial model of vegetation and carbon cycles (Meissner et al., 2003) based on the Hadley Center model: Top-down Representation of Interactive Foliage and Flora Including Dynamics (TRIFFID). Land processes are modeled via the Met Office surface exchange scheme 1 (MOSES1) (Cox, 2001). Continental ice sheets are assumed to be constant in our model configuration. In contrast, sea ice is calculated with a thermo-dynamic sea ice model. The ocean component is the Modular Ocean Model 2 (MOM2) and consists of 19 vertical layers and, as with the atmospheric component, is forced by monthly climatological wind data from NCAR/NCEP. Subgrid-scale eddy mixing is parameterized according to Gent and McWilliams (1990), the vertical diffusivity parameter in the Southern Ocean is increased as in Keller et al. (2012), tidally induced diapycnal mixing over rough topography is computed according to the scheme by Simmons et al. (2004), and an anisotropic viscosity scheme (Large et al., 2001) is applied in the tropics. 

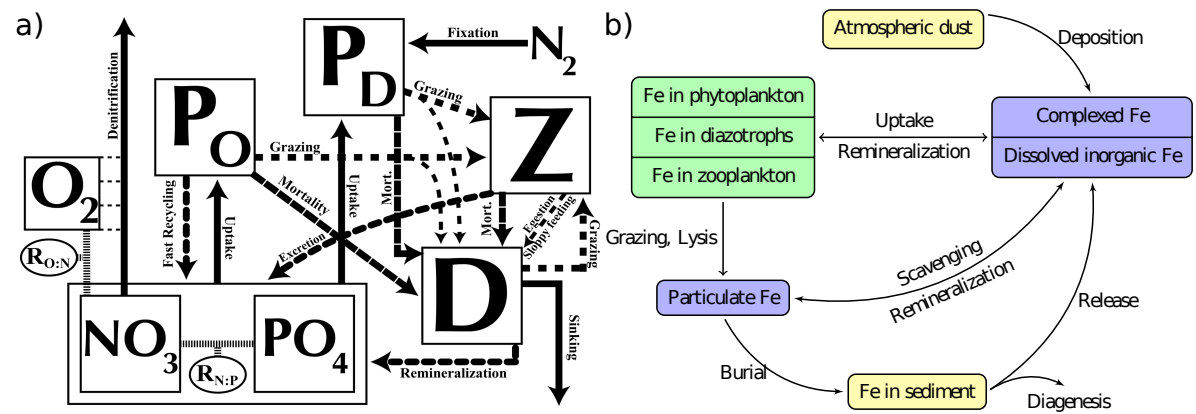

Figure 1. (a) Schematic of the previous ecosystem model, which did not include a dynamic iron cycle, illustrating the flux of material between model variables (reprinted from Fig. 1 in Keller et al., 2012). (b) Schematic of the new iron cycle that is implemented into the previous model. Assuming that complexation and dissociation are very fast processes, the two new iron tracer are dissolved iron which is assumed to be bioavailable and particulate iron which is assumed to not be bioavailable. Yellow boxes indicate external reservoirs of iron, blue boxes not living iron species in the ocean and green boxes the living iron species in the ocean.

\subsection{The marine biogeochemical model}

The marine biogeochemical model used here was developed and extended by Oschlies and Garçon (1999), Schmittner et al. (2005), Schmittner et al. (2008) and Keller et al. (2012). The model is a NPZD type of model with nutrients $(\mathrm{N})$, phytoplankton $(\mathrm{P})$, zooplankton $(\mathrm{Z})$ and detritus $(\mathrm{D})$. Sources and sinks are described in the following and illustrated in Fig. 1a, for the full equations see Schmittner et al. (2008) and Keller et al. (2012).

The model is nitrogen-based, but has two dissolved inorganic nutrient pools, nitrate $\left(\mathrm{NO}_{3}\right)$ and phosphate $\left(\mathrm{PO}_{4}\right)$. Redfield stoichiometry is used to convert the tracer mass into carbon, phosphorus or oxygen when necessary. There are two types of phytoplankton, one of which represents nitrogen fixing phytoplankton types (diazotrophs, $P_{\mathrm{D}}$ ). Since they can fix dinitrogen into bioavailable forms, these diazotrophs are not limited by nitrate concentrations. In contrast, the other phytoplankton class $\left(P_{\mathrm{O}}\right)$, which represents all non-nitrogen fixing phytoplankton, is limited by nitrate and phosphate. Microbial loop dynamics and dissolved organic matter cycling are parameterized via a fast recycling scheme that directly returns a fraction of phytoplankton into inorganic nutrients. Non-grazing related phytoplankton mortality also results in the production of detritus. Zooplankton (Z) graze on ordinary phytoplankton, diazotrophs, themselves and detritus (D). Growth and assimilation efficiency terms determine the fraction of prey biomass that is assimilated into biomass, respired, excreted or lost to detritus via sloppy feeding, egestion, and fecal pellet production. Zooplankton mortality also produces detritus. Detritus is considered as a tracer with horizontal advection and diffusion, but primarily sinks through the water column. A temperature-dependant function simulates microbial decomposition and remineralization to convert detritus back into inorganic nutrients and carbon. At the seafloor all detritus is instantly converted back into inorganic nutrients and carbon to simulate benthic decomposi- tion and remineralization. During the remineralization of detritus, oxygen $\left(\mathrm{O}_{2}\right)$, which is also a dynamically calculated tracer, is consumed. When oxygen levels fall below a threshold of $5 \mathrm{mmol} \mathrm{m}^{-3}$, anaerobic remineralization sets in at rates 3 times slower than aerobic remineralization, and with associated nitrogen losses representing the combined effects of denitrification and anammox.

Using fixed Redfield ratios between carbon and nitrogen, dissolved inorganic carbon (DIC) and alkalinity (ALK) are also included in the model. For a more complete description of the biogeochemical model also see the complete model code in the Supplement or at https://thredds.geomar.de/ thredds/fileServer/peerReviewData/nickelsen-et-al_gmd_ 2014/Nickelsen-et-al_GMD_2014_submitted.zip.

\subsection{The new dynamic iron cycle}

The iron cycle described here (Fig. 1b) largely follows Parekh et al. (2004, 2005) and Galbraith et al. (2010). Sources and sinks of the modeled iron cycle are explained first with description of parameterizations for iron limitation, scavenging, remineralization, sediment release and dust deposition given in the subsequent sections.

\subsubsection{Sources and sinks of iron}

The iron cycle is simulated with the addition of two new physical tracers, dissolved iron $(\mathrm{Fe})$ and particulate iron $\left(\mathrm{Fe}_{\mathrm{P}}\right)$, to the marine biogeochemical model. The dissolved iron includes free iron and complexed iron, both of which are assumed to be entirely bioavailable.

The concentration of each tracer changes according to the following equation

$\frac{\partial C}{\partial t}=\operatorname{Tr}+S$

where $\operatorname{Tr}$ denotes physical transport including advection, isopycnal and diapycnal diffusion. $S$ represents the source 
Table 1. Parameters that are new or different from Keller et al. (2012) with parameter name, description, value, range tested and unit. References for the parameters are given as footnotes. If no units are given in the reference column, reference units are equal to model units given in the last column.

\begin{tabular}{|c|c|c|c|c|c|}
\hline Parameter & Description & Reference & Value & Tested range & Unit \\
\hline$\alpha_{\mathrm{min}}^{\mathrm{chl}}$ & Minimum slope in the photosynthesis-irradiance curve & $18.4-73.6^{\mathrm{a}}$ & 18.4 & - & $\mu \mathrm{gC}\left(\mathrm{gChl}^{-1}\left(\mathrm{~W} \mathrm{~m}^{-2}\right)^{-1} \mathrm{~s}^{-1}\right.$ \\
\hline$\alpha_{\max }^{\mathrm{chl}}$ & Maximum slope in the photosynthesis-irradiance curve & $18.4-73.6^{\mathrm{a}}$ & 73.6 & - & $\mu \mathrm{gC}\left(\mathrm{gChl}^{-1}\left(\mathrm{~W} \mathrm{~m}^{-2}\right)^{-1} \mathrm{~s}^{-1}\right.$ \\
\hline$\theta_{\max }$ & Maximum Chl: $\mathrm{C}$ ratio, abundant iron & $0.007-0.072^{\mathrm{a}}$ & 0.04 & - & $\mathrm{gChl}\left(\mathrm{gC}^{-1}\right.$ \\
\hline$\theta_{\min }$ & Minimum Chl : $\mathrm{C}$ ratio, extreme iron limitation & $0.007-0.072^{\mathrm{a}}$ & 0.01 & - & $\mathrm{gChl}\left(\mathrm{gC}^{-1}\right.$ \\
\hline $\mathrm{kFe}_{\max }$ & Maximum half-saturation constant for iron uptake & $0.19-1.14^{\mathrm{b}}$ & 0.4 & $0.3-0.4$ & $\mu \mathrm{mol} \mathrm{Fe}{ }^{-3}$ \\
\hline $\mathrm{kFe}_{\min }$ & Minimum half-saturation constant for iron uptake & $0.035^{\mathrm{c}}$ & 0.04 & $0.035-0.04$ & $\mu \mathrm{mol} \mathrm{Fe} \mathrm{m}^{-3}$ \\
\hline$P_{\max }$ & Phytoplankton biomass above which $\mathrm{kFe}$ increases & $0.15^{\mathrm{d}}$ & 0.15 & $0.1-0.15$ & $\mathrm{mmolNm}^{-3}$ \\
\hline $\mathrm{kFe}_{\mathrm{D}}$ & Diazotroph half-saturation constant for iron uptake & $0.06^{\mathrm{e}}$ & 0.1 & $0.06-0.12$ & $\mu \mathrm{mol} \mathrm{Fe} \mathrm{m}^{-3}$ \\
\hline$R_{\mathrm{Fe}}: \mathrm{N}$ & $\mathrm{Fe}: \mathrm{N}$ uptake ratio & $5 \mu \mathrm{molFe}(\mathrm{molC})^{-1 \mathrm{f}}$ & 66.25 & $33.125-66.25$ & $\mu \mathrm{molFe}(\mathrm{molN})^{-1}$ \\
\hline$L_{\mathrm{T}}$ & Total ligand concentration & $1^{\mathrm{g}}$ & 1 & $0.6-1.2$ & $\mu \mathrm{mol}$ lig $\mathrm{m}^{-3}$ \\
\hline $\mathrm{Fe}: \mathrm{P}_{\text {sed }}$ & $\mathrm{Fe}: \mathrm{P}$ ratio for sedimentary iron source & $0.072 \mathrm{molFe}(\mathrm{molP})^{-1 \mathrm{~h}}$ & 0.004 & $0.001-0.01$ & $\mathrm{molFe}(\mathrm{molP})^{-1}$ at $0^{\circ} \mathrm{C}$ \\
\hline$K \mathrm{FeL}$ & $\mathrm{Fe}$-ligand stability constant & $10^{11}-10^{12 \mathrm{i}}$ & $10^{11.5}$ & $10^{11}-10^{12}$ & $\left(\operatorname{mol} \operatorname{lig}\left(1^{-1}\right)\right)^{-1}$ \\
\hline $\mathrm{kFe}_{\text {org }}$ & Organic matter dependent scavenging rate & $0.5^{\mathrm{g}}$ & 0.45 & $0.45-0.5$ & $(\mathrm{gC})^{-0.58}\left(\mathrm{~m}^{3}\right)^{0.58} \mathrm{~d}^{-1}$ \\
\hline $\mathrm{kFe}_{\text {prp }}$ & Inorganic scavenging rate & $0.003^{\mathrm{d}}$ & 0.005 & $0.003-0.005$ & $\mathrm{~d}^{-1}$ \\
\hline $\mathrm{O}_{2 \min }$ & Minimum $\mathrm{O}_{2}$ concentration for iron oxidation & $5^{j}$ & 5 & $0-5$ & $\mathrm{mmolO}_{2} \mathrm{~m}^{-3}$ \\
\hline
\end{tabular}

minus sink terms. All dissolved iron $(\mathrm{Fe})$ is assumed to be bioavailable whereas particulate iron $\left(\mathrm{Fe}_{\mathrm{P}}\right)$ is not. Dissolved iron is taken up by phytoplankton and remineralized by grazing or microbial decomposition processes, biotically derived particulate iron is produced whenever organic detritus is produced. These biotic fluxes are calculated from the nitrogenbased rates using a fixed $\mathrm{Fe}: \mathrm{N}$ ratio $\left(R_{\mathrm{Fe}: \mathrm{N}}\right)($ Table 1$)$. Observations indicate highly variable $\mathrm{Fe}: \mathrm{N}$ ratios (Price, 2005), yet the usage of a fixed $\mathrm{Fe}: \mathrm{N}$ ratio is a pragmatic choice that reduces computational costs as it circumvents the need to calculate iron concentrations within each biological tracer. The sources and sinks of the two additional iron tracers are described by

$$
\begin{aligned}
S(\mathrm{Fe}) & =R_{\mathrm{Fe}: \mathrm{N}}\left(\mu_{\mathrm{P}} P_{\mathrm{O}}+(\gamma-\bar{\omega})\right. \\
& \left.\cdot\left(\mathrm{graz}_{\mathrm{P}}+\mathrm{graz}_{\mathrm{D}}+\mathrm{graz}_{\mathrm{Det}}+\mathrm{graz}_{\mathrm{Z}}\right)-J_{\mathrm{O}} P_{\mathrm{O}}-J_{\mathrm{D}} P_{\mathrm{D}}\right) \\
& +\mu_{\mathrm{Fe}}-\mathrm{fe}_{\mathrm{orgads}}-\mathrm{fe}_{\mathrm{prp}}+\mathrm{fe}_{\mathrm{sed}}+\mathrm{fe}_{\mathrm{dust}}, \\
S\left(\mathrm{Fe}_{\mathrm{P}}\right) & =R_{\mathrm{Fe}: \mathrm{N}}((1-\gamma) \\
& \cdot\left(\mathrm{graz}_{\mathrm{P}}+\mathrm{graz}_{\mathrm{D}}+\mathrm{graz}_{\mathrm{Det}}+\mathrm{graz}_{\mathrm{Z}}\right)+\text { morp }+\operatorname{morp}_{\mathrm{D}} \\
& \left.+ \text { morz }-\mathrm{graz}_{\mathrm{Det}}\right)-\mu_{\mathrm{Fe}_{\mathrm{P}}}+\mathrm{fe}_{\mathrm{orgads}}+\mathrm{fe} \mathrm{prp}_{\mathrm{prp}}-w_{\mathrm{D}} \frac{\partial \mathrm{Fe}_{\mathrm{P}}}{\partial z} .
\end{aligned}
$$

The first term in Eq. (2), $\left(\mu_{\mathrm{P}} P_{\mathrm{O}}\right)$ is a temperature-dependent fast remineralization function that represents recycling of iron bound to phytoplankton-derived organic matter via the microbial loop and dissolved organic matter cycling. The second term represents iron excretion by zooplankton, which is calculated as the difference between their assimilation and growth efficiency coefficients $(\gamma-\bar{\omega})$ for the sum of all grazing on phytoplankton $\left(\operatorname{graz}_{\mathrm{P}}\right)$, diazotrophs $\left(\mathrm{graz}_{\mathrm{D}}\right)$, detritus $\left(\mathrm{graz}_{\mathrm{Det}}\right)$ and themselves $\left(\mathrm{graz}_{\mathrm{Z}}\right)$. The third and fourth terms represent the uptake of dissolved iron by ordinary phytoplankton and diazotrophs $\left(J_{\mathrm{O}} P_{\mathrm{O}}, J_{\mathrm{D}} P_{\mathrm{D}}\right)$. The fifth term,
$\left(\mu_{\mathrm{Fep}}\right)$, represents the temperature-dependent decomposition and remineralization of particle-bound iron. The next two terms represent abiotic iron cycling, which is characterized by the loss of bioavailable, dissolved iron through scavenging. Scavenging is modeled here as two distinct processes: adsorption of iron to organic material (fe $\mathrm{orgads}_{\text {) }}$ ) and precipitation and colloidal formation with subsequent aggregation $\left(\mathrm{fe}_{\mathrm{prp}}\right)$ described in detail below. The final two terms represent the external sources of iron that are added to the water column from sediment release ( $\mathrm{fe}_{\mathrm{sed}}$ ) and dust deposition (fe $\mathrm{fust}_{\text {dust }}$.

In Eq. (3) the biotic sources and sinks of particulate iron are equal to the sources and sinks of detritus (see Eq. (6) in Keller et al., 2012). Thus, the first term, which is calculated as one minus the zooplankton assimilation efficiency $(1-\gamma)$ for the sum of all grazing (see coefficients above), represents the production of iron-containing detritus from sloppy feeding, egestion, or fecal pellet release. The next three terms represent the production of iron-containing detritus from the mortality of ordinary phytoplankton $\left(m_{P_{\mathrm{O}}} P_{\mathrm{O}}\right)$, diazotrophs $\left(m_{P_{\mathrm{D}}} P_{\mathrm{D}}\right)$ and zooplankton $\left(m_{\mathrm{Z}} Z^{2}\right)$. The fifth term accounts for the removal of particle-bound iron by zooplankton grazing $\left(\operatorname{graz}_{\text {Det }}\right)$. The sixth term, $\left(\mu_{\mathrm{Fe}_{\mathrm{P}}}\right)$, represents the loss of particulate iron due to temperature-dependent decomposition and remineralization. The next two terms represent the abiotic scavenging fluxes ( $\mathrm{fe}_{\text {orgads }}$ and $\mathrm{fe}_{\mathrm{prp}}$ ) that add to the particulate iron pool. The final term, $w_{\mathrm{D}} \frac{\partial \mathrm{Fe}_{\mathrm{P}}}{\partial z}$, accounts for the vertical sinking of particulate iron with a sinking speed $w_{\mathrm{D}}$ that increases linearly with depth (see Keller et al., 2012; Schmittner et al., 2008). Depending on the redox state of seafloor sediments, particulate iron that sinks to the bottom is either instantly remineralized or buried in the sediments (see Sect. 2.3.4). 


\subsubsection{Phytoplankton iron limitation}

Iron limitations of ordinary and diazotrophic phytoplankton is described in terms of Monod functions as in Aumont and Bopp (2006). For ordinary phytoplankton the formulation of iron limitation is based on the observation that larger cells have higher iron half-saturation constants than smaller ones (Timmermans et al., 2004). As in Aumont and Bopp (2006) we assume that an increase of phytoplankton biomass is mainly due to increases in cell size so that the half-saturation constant of iron limitation for ordinary phytoplankton varies with their biomass $P_{\mathrm{O}}$ :

$P_{1}=\min \left(P_{\mathrm{O}}, P_{\max }\right)$,

$P_{2}=\max \left(0, P_{\mathrm{O}}-P_{\max }\right)$,

$\mathrm{kFe}_{\mathrm{O}}=\frac{\mathrm{kFe}_{\min } P_{1}+\mathrm{kFe}_{\max } P_{2}}{P_{1}+P_{2}}$

The three parameters used for this formulation from Aumont and Bopp (2006) are the phytoplankton biomass above which the iron uptake half-saturation constant starts to increase, $P_{\max }$, and the minimum $\left(\mathrm{kFe}_{\min }\right)$ and maximum iron uptake half-saturation constants $\left(\mathrm{kFe}_{\max }\right)$. The iron uptake halfsaturation constant for diazotrophs $\left(\mathrm{kFe}_{\mathrm{D}}\right)$ is set as a nonvarying parameter to reduce the number of parameters and to reflect the stronger constraint that iron imposes on the growth of small, diazotrophic phytoplankton (Mills et al., 2004; Moore and Doney, 2007). Using these half-saturation constants, iron limitation variables (felim $\mathrm{O}$, felim $\mathrm{D}$ ) for both, ordinary and diazotrophic phytplankton are calculated:

$\begin{aligned} \text { felim }_{\mathrm{O}} & =\frac{\mathrm{Fe}}{\mathrm{kFe}_{\mathrm{O}}+\mathrm{Fe}}, \\ \text { felim }_{\mathrm{D}} & =\frac{\mathrm{Fe}}{\mathrm{kFe}_{\mathrm{D}}+\mathrm{Fe}} .\end{aligned}$

Then as in Keller et al. (2012), these limiting variables are included in the calculation of the potential phytoplankton maximum growth rates to reflect the necessity of iron for photosynthesis, the reduction of nitrate to ammonium, and a number of other key cellular processes (Galbraith et al., 2010) (i.e., we assume that iron must be available before photosynthesis or the uptake and utilization of nitrogen and phosphate is possible).

$J_{\mathrm{O}}^{\max }=a \exp \left(T / T_{b}\right)$ felim $\mathrm{O}$,

$J_{\mathrm{D}}^{\max }=c_{\mathrm{D}} \max \left(0, a \exp \left(T / T_{b}-2.61\right)\right.$ felim $\left.\mathrm{D}\right)$,

where the maximum growth at $0{ }^{\circ} \mathrm{C}$ is multiplied with an $e$ folding temperature dependence term $T / T_{b}$, which produces a temperature constrained growth rate curve that is identical to the Eppley curve (Eppley, 1972) except at very high ocean temperatures, and the iron limitation variable. As in Schmittner et al. (2008) and Keller et al. (2012) diazotroph growth is reduced by using a handicap $c_{\mathrm{D}}$ and a stronger temperature dependence so that growth is inhibited below $15^{\circ} \mathrm{C}$.
In addition to the constraints that iron limitation imposes on the maximum potential growth rate, iron is assumed to influence phytoplankton light harvesting capabilities. Phytoplankton light limited growth is basically calculated as in Keller et al. (2012) and Schmittner et al. (2008) using

$J_{(\mathrm{O} \text { or D }) I}=\frac{J_{(\mathrm{O} \text { or D })}^{\max } \alpha I}{\left[\left(J_{(\mathrm{O} \text { or D })}^{\max }\right)^{2}+(\alpha I)^{2}\right]^{1 / 2}}$.

For the full calculation of the depth averaged light limitation with a triangular shaped diurnal irradiance cycle see Schmittner et al. (2009) and Keller et al. (2012). Here Eq. (11) for light limited growth is modified following Galbraith et al. (2010) by making the initial slope of the photosynthesisirradiance curve $\alpha$ chlorophyll specific ( $\left.\alpha^{\mathrm{chl}}\right)$ and making light limitation dependent on a $\mathrm{Chl}: \mathrm{C}$ ratio $\theta$. Both, $\alpha^{\text {chl }}$ and $\theta$, are in turn dependent on iron concentrations. In this way the dependence of light harvesting capabilities and chlorophyll synthesis on iron concentrations as suggested by field and culture experiments (Hopkinson et al., 2007; Price, 2005) is represented in the model. Thus, the phytoplankton light limited growth becomes

$J_{(\mathrm{O} \text { or D }) I}=\frac{J_{(\mathrm{O} \text { or } \mathrm{D})}^{\max } \alpha^{\mathrm{chl}} \theta_{(\mathrm{O} \text { or } \mathrm{D})} I}{\left[\left(J_{(\mathrm{O} \text { or } \mathrm{D})}^{\max }\right)^{2}+\left(\alpha^{\mathrm{chl}} \theta_{(\mathrm{O} \text { or } \mathrm{D})} I\right)^{2}\right]^{1 / 2}}$,

where $J_{(\mathrm{O} \text { or D })}^{\max }$ are the maximum potential growth rates and $I$ is irradiance. The realized $\mathrm{Chl}: \mathrm{C}$ ratios $\theta_{(\mathrm{O} \text { or D) }}$ are calculated as

$\theta_{\mathrm{O}}=\theta_{\min }+\left(\theta_{\max }-\theta_{\min }\right)$ felim $\mathrm{O}$,

$\theta_{\mathrm{D}}=\theta_{\text {min }}+\left(\theta_{\text {max }}-\theta_{\text {min }}\right)$ felim ${ }_{\mathrm{D}}$,

and the initial slope of the PI-curve as

$\alpha_{\mathrm{O}}^{\mathrm{chl}}=\alpha_{\min }^{\mathrm{chl}}+\left(\alpha_{\max }^{\mathrm{chl}}-\alpha_{\min }^{\mathrm{chl}}\right)$ felim $\mathrm{O}$,

$\alpha_{\mathrm{D}}^{\mathrm{chl}}=\alpha_{\min }^{\mathrm{chl}}+\left(\alpha_{\max }^{\mathrm{chl}}-\alpha_{\min }^{\mathrm{chl}}\right)$ felim ${ }_{\mathrm{D}}$

The iron limitation variables felim ${ }_{O, D}$ are used here to create a linear change between minimum and maximum parameter values following Galbraith et al. (2010). The impact of making $\alpha^{\text {chl }}$ and $\theta$ functions of iron concentrations is comprehensively described by Galbraith et al. (2010). They find that this formulation leads to an improved agreement with observations of surface phosphate concentrations and export production, a more pronounced seasonal cycle of primary production and a stronger phytoplankton growth limitation in the Southern Ocean.

\subsubsection{Iron scavenging and remineralization}

Scavenging, which converts dissolved iron into colloidal and particulate forms, is an important part of the marine iron 
cycle. Iron speciation determines whether iron is subject to scavenging or stays dissolved as an organic complex bound to an organic ligand. Since the association and dissociation of iron to ligands occurs on timescales $<1$ day (Gledhill and Buck, 2012), we follow Parekh et al. (2004) in assuming that this process occurs rapidly enough so that a chemical equilibrium is reached between free iron, free ligands and organic iron complexes. Thus, we avoid the need to add computationally costly tracers for free ligands and organic iron complexes. As in Parekh et al. (2004) the concentration of free iron $\mathrm{Fe}_{\text {prime }}$ that is subject to scavenging can then be calculated from the following equations assuming a chemical equilibrium between free iron, free ligands and organic iron complexes.

$L=\mathrm{FeL}+L_{\text {prime }}$

$\mathrm{Fe}=\mathrm{FeL}+\mathrm{Fe}_{\text {prime }}$

$K_{\mathrm{FeL}}=\frac{\mathrm{FeL}}{\mathrm{Fe}_{\text {prime }} L_{\text {prime }}}$

The total ligand concentration $(L)$ is assumed to be a globally constant model parameter due to uncertainties in the sources and sinks and to lower numerical costs. Ligand-bound iron is denoted by FeL, the free ligand concentration by $L_{\text {prime}}$, the total dissolved iron concentration by $\mathrm{Fe}$ and the equilibrium constant between free iron and ligands and the organic complexes by $K_{\mathrm{FeL}}$. Solving for $\mathrm{Fe}_{\text {prime }}$ gives

$\mathrm{Fe}_{\text {prime }}=\frac{-A+\left(A^{2}+4 K_{\mathrm{FeL}} \mathrm{Fe}\right)^{0.5}}{2 K_{\mathrm{FeL}}}$,

$A=1+K_{\mathrm{FeL}}(L-\mathrm{Fe})$,

where the equilibrium constant $K_{\mathrm{FeL}}$ is considered a globally constant parameter whose value is based on a compilation by Gledhill and Buck (2012).

Once $\mathrm{Fe}_{\text {prime }}$ is known, scavenging can be calculated. The first scavenging process is the adsorption of free dissolved inorganic iron onto organic material. Following Parekh et al. (2005) and Galbraith et al. (2010) and based on the observations by Honeyman et al. (1988), the adsorption rate in the model (fe $\mathrm{ergads}_{\text {s }}$ ) is dependent on the particulate organic matter concentration (Detr), the concentration of free iron $\left(\mathrm{Fe}_{\text {prime }}\right)$ and the scavenging rate $\left(\mathrm{kFe}_{\text {org }}\right)$.

$\mathrm{fe}_{\text {orgads }}=\mathrm{kFe}_{\text {org }} \mathrm{kFe}_{\text {prime }}\left(\operatorname{Detr} R_{\mathrm{C}: \mathrm{N}} M_{\mathrm{C}}\right)^{0.58}$

The carbon to nitrogen ratio is denoted by $R_{\mathrm{C}: \mathrm{N}}$ and the molar mass of carbon by $M_{\mathrm{C}}=12.011 \mathrm{~g} \mathrm{~mol}^{-1}$. In the second scavenging process $\left(\mathrm{fe}_{\mathrm{prp}}\right.$ ), iron precipitates and forms colloids which can subsequently aggregate into larger particles. This more inorganic process is represented in the model using a linear scavenging rate that is independent of the organic particle concentration:

$\mathrm{fe}_{\text {prp }}=\mathrm{kFe}_{\text {prp }} \mathrm{Fe}_{\text {prime }}$.
The scavenging rate constant for precipitation, colloid formation and aggregation is denoted by $\mathrm{kFe}_{\text {prp. }}$. Both scavenging rates are set to zero when oxygen concentrations fall below a threshold $\mathrm{O}_{2 \min }$ (Table 1) as in the model by Galbraith et al. (2010) because iron oxidation rates are reduced and elevated iron concentrations are repeatedly observed under low oxygen concentrations (Hopkinson and Barbeau, 2007; Moffett et al., 2007; Rijkenberg et al., 2012). However, the threshold assumption is a pragmatic choice and there is still uncertainty in the impact of the reduced iron oxidation rates (Hopkinson and Barbeau, 2007). We therefore test the threshold assumption by running an additional 1000 year simulation in which scavenging is permitted when oxygen levels fall below $\mathrm{O}_{2 \mathrm{~min}}$ (see Supplementary Fig. S1). The effect is small and might be important only locally.

Remineralization and sinking of particulate iron is proportional to that of particulate nitrogen (e.g., detritus). Thus, the temperature-dependent remineralization rate is calculated as

$\mu_{\mathrm{Fe}}=\mu_{\mathrm{d} 0} \exp \left(T / T_{b}\right) \mathrm{Fe}_{\mathrm{P}}$,

where $\mu_{\mathrm{d} 0}$ is the remineralization rate parameter for both particulate iron and particulate organic nitrogen at $0^{\circ} \mathrm{C}$.

\subsubsection{Sediment iron cycling}

Observations of iron release or burial in sediments have shown that these processes are dependent on the sediment redox state, which is primarily determined by the oxygen content of the overlying water column (Noffke et al., 2012; Severmann et al., 2010; Dale et al., 2015), the ambient temperature (Arnosti et al., 1998; Sanz-Lázaro et al., 2011) and the amount of organic matter that reaches the sea floor and is remineralized therein (Elrod et al., 2004).

Here we follow the model of Galbraith et al. (2010) to calculate the flux of iron from the sediment $\left(\mathrm{fe}_{\mathrm{sed}}\right)$. Iron is released with a constant ratio $\left(\mathrm{Fe}: \mathrm{P}_{\mathrm{sed}}\right)$ of iron to particulate organic phosphorus reaching the sediment $\left(\mathrm{F}_{\mathrm{POP}}\right)$. Particulate iron that sinks out of the bottom ocean layer is permanently removed from the ocean, as long as oxygen concentrations are greater than the suboxic threshold $\mathrm{O}_{2 \min }$ (cf. diagenesis in Fig. 1b). However, if bottom water oxygen concentrations are below $\mathrm{O}_{2 \mathrm{~min}}$, then the environment is assumed to be strongly reducing and all particulate iron sinking to the sediment $\left(\mathrm{F}_{\mathrm{Fe}_{\mathrm{P}}}\right)$ is released back into the water column, producing dissolved iron:

$\mathrm{fe}_{\mathrm{sed}}=\mathrm{Fe}: \mathrm{P}_{\mathrm{sed}} \mathrm{F}_{\mathrm{POP}} \exp \left(T / T_{b}\right) \quad\left(\mathrm{O}_{2}>\mathrm{O}_{2 \min }\right)$,
$\mathrm{fe}_{\mathrm{sed}}=\mathrm{Fe}: \mathrm{P}_{\mathrm{sed}} \mathrm{F}_{\mathrm{POP}} \exp \left(T / T_{b}\right)+\mathrm{F}_{\mathrm{Fep}} \quad\left(\mathrm{O}_{2} \leq \mathrm{O}_{2 \min }\right)$.

The ratio between iron released from the sediment and phosphorus in particulate matter that sinks into the sediment is denoted by $\mathrm{Fe}: \mathrm{P}_{\text {sed }}$ and is based on the observation of such a constant ratio by Elrod et al. (2004). Note that their observation relies on measurements from the California coast 

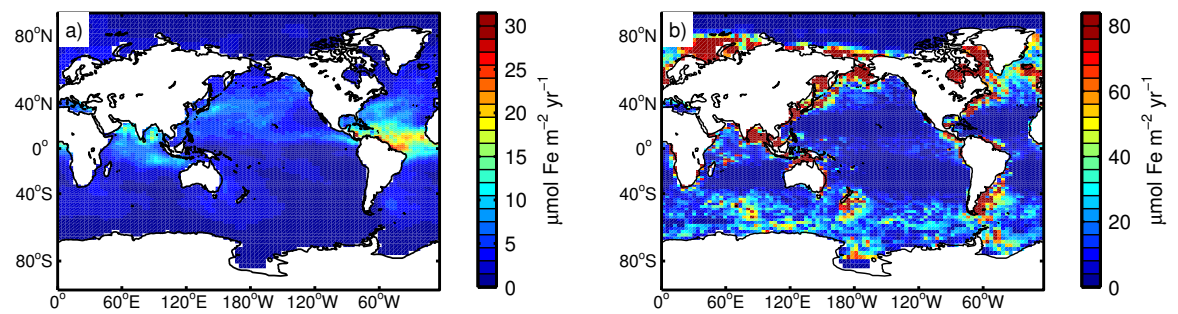

Figure 2. Annually averaged atmospheric deposition and sediment release of iron. (a) A preindustrial estimate of climatological annually averaged dust deposition (Luo et al., 2008). (b) Sedimentary iron release as simulated with the model according to Eqs. (25) and (26). Note the different color scales.

that we have applied to the whole ocean here. We recognize that the relation can of course vary globally because of, for instance, different microbial communities and chemical environments. However, the relationship by Elrod et al. (2004) is empirically based and formulated so that it allows the sediment source of iron to adjust when the amount of organic carbon supplied to the sediment changes. In some regions this may cause a feedback to occur since the released iron affects productivity and organic matter export, which in turn affects sediment iron release. This interactive response of the sediment source could be important in sensitivity studies.

Due to the observation of temperature-dependent remineralization (Arnosti et al., 1998; Sanz-Lázaro et al., 2011), the importance of sediment release for the iron reservoir and an improvement of agreement between our simulated and observed iron concentrations particularly in the Southern Ocean, we assume that remineralization of iron in the sediment is temperature dependent by multiplying with a temperature-dependent factor $\left(\exp \left(T / T_{b}\right)\right.$ where $T_{b}=$ $\left.15.65^{\circ} \mathrm{C}\right)$. The average observed iron concentrations in the whole water column south of $40^{\circ} \mathrm{S}$ are $0.52 \mathrm{nM}$, simulated concentrations are $0.67 \mathrm{nM}$ without and $0.53 \mathrm{nM}$ with the temperature dependence. The assumption of temperaturedependent iron release is tested and discussed further in Sect. 4. Riverine sources of iron are scavenged quickly at river mouths so that they are not viewed as an important source of iron to the ocean. Yet, the scavenged iron from rivers can reach the sediment and under low bottom water oxygen concentrations are released again as dissolved iron to the water column (Severmann et al., 2010). Equation (26) allows that locally, i.e. under bottom water oxygen concentrations smaller than $\mathrm{O}_{2 \mathrm{~min}}$, more iron can be released from the sediment than reaches it to reflect the massive iron release under low bottom water oxygen concentrations (Noffke et al., 2012) and implicitly also representing the riverine source of iron to the sediment.

The importance of the sedimentary iron sources for surface ocean biogeochemical cycling has been emphasized in previous observational (Noffke et al., 2012) and modeling studies (Moore and Braucher, 2008; Tagliabue et al., 2009). However, in coarse-resolution three-dimensional ocean circula- tion models the bathymetry defined by the lowest grid boxes can strongly differ from the actual bathymetry of the ocean and with that the depth at which transfers between sediment and water column occur. Thus, a subgrid-scale bathymetry is applied as in Aumont and Bopp (2006), Moore and Braucher (2008) and Somes et al. (2013) where the model bathymetry is compared to a bathymetry data set, here the Earth Topography 2 Minute Gridded Global Relief Data (ETOPO2v2) (US Dept. of Commerce et al., 2006). For each horizontal grid point and at each depth level the fraction of the bottom area of the model box that is actually ocean floor within this box is calculated. This fraction determines then the fraction of organic matter that is treated as if it hits the sea floor. The resulting sediment flux of iron is illustrated in Fig. 2. The role of the sediment fluxes for the iron cycle will also be investigated further in a subsequent study.

\subsubsection{Dust deposition of iron}

An important source of iron in the open ocean comes from the deposition of iron-containing dust (Mahowald et al., 2009). The dust is eroded in arid terrestrial areas, for example, the Sahara or some parts of Australia, and then transported in the atmosphere to eventually be deposited in the ocean. We simulate this source of iron using a climatological preindustrial estimate of monthly iron deposition (Luo et al., 2008). This estimate of iron deposition is derived from an atmospheric model that simulates the transport of dust in the atmosphere (Luo et al., 2008). During the transport in the atmosphere Luo et al. (2008) assume a constant $3.5 \%$ fraction of iron in dust and that the solubility of iron increases due to reduction of $\mathrm{Fe}(\mathrm{III})$ to $\mathrm{Fe}(\mathrm{II})$ in acidic clouds. They can reproduce the observation of generally lower iron solubility at areas of high dust deposition and higher solubility at low dust deposition (Baker and Croot, 2010). Other estimates of total iron deposition of $56.7 \mathrm{GmolFe} \mathrm{yr}^{-1}$ (Mahowald et al., 2006) or $29.3 \mathrm{GmolFe} \mathrm{yr}^{-1}$ (Mahowald et al., 2010), assuming $3.5 \%$ iron in dust and a globally constant $1 \%$ solubility do not reproduce the solubility pattern and are thus considerably larger than the total iron deposition of $2.1 \mathrm{GmolFe} \mathrm{yr}^{-1}$ by Luo et al. (2008). At every ocean tracer 
time step we calculate the amount of iron that is deposited from the monthly values using linear interpolation (Fig. 2).

\subsection{Parameter choices, spin-up and assumptions}

Only the parameters associated with the iron cycle are new (Table 1). All other parameters are as in Keller et al. (2012). Whenever possible model parameters were based on observed values or taken from previously evaluated modeling studies. For parameters that are poorly constrained, the parameters were chosen within an observed range of values, if possible, to best simulate observed biogeochemical properties. In practice this involved varying the parameters individually, one by one, within the ranges given in (Table 1). The goal was to maximize agreement of surface macronutrients to observations and iron concentrations to the sparse observations while keeping the agreement of subsurface biogeochemical properties such as phosphate, nitrate and oxygen concentrations to observations similar to the agreement in the previous model version. Before the comparison to observations and the previous model version, the model was spun up for 10000 years using preindustrial boundary conditions for insolation and a fixed atmospheric $\mathrm{CO}_{2}$ concentration of 283 uatm.

Here we summarize important assumptions that have been made to model the iron cycle. First, a fixed $\mathrm{Fe}: \mathrm{N}$ ratio is used for the biological state variables. This was done to minimize computational expenses and because the Fe stoichiometry of plankton is poorly constrained. Second, the ligand concentration is assumed to be globally constant since there are still a lot of uncertainties in the sources and sinks of iron-binding ligands (Völker and Tagliabue, 2015). Third, the sinking speeds of particulate nitrogen and iron are identical. Finally, the only two external sources of iron to the ocean that are considered are dust deposition and sediment release because other sources have been shown to be of minor importance (Tagliabue et al., 2014a). All of these assumptions are made to keep the computational costs low, which is necessary for long-term model runs such as paleo-simulations or running multiple sensitivity tests to equilibrium (e.g. to keep the model as an EMIC). This is also the reason why the iron cycle is described with only two model tracers, dissolved and particulate iron. Due to the low number of parameters relative to other more complex models, the model also relies on less unconstrained parameters and has a smaller degree of freedom.

\section{Model evaluation}

The evaluation in this section focuses exclusively on the iron cycle and the other biogeochemical properties of the model because the physical (Weaver et al., 2001) and terrestrial components (Meissner et al., 2003) have been evaluated in detail in previous studies. Comparisons to the World Ocean

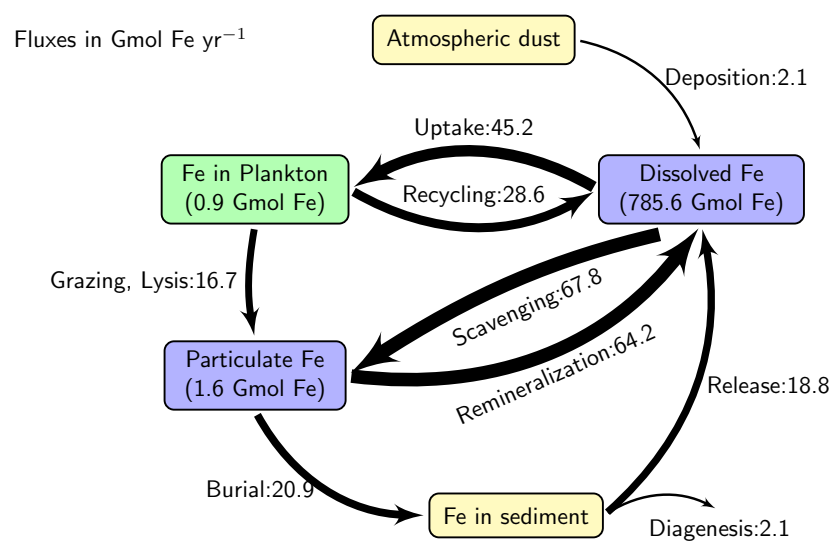

Figure 3. Global annually averaged iron fluxes as simulated with

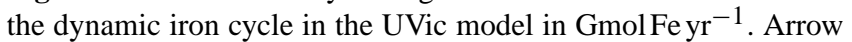
thickness is scaled with the size of the fluxes. The numbers inside the boxes denote the globally integrated amounts of iron in the respective pools in Gmol Fe.

Atlas 2009 (WOA09) (Garcia et al., 2010a, b), and Global Data Analysis Project (GLODAP) (Key et al., 2004) and an iron concentration compilation database (Tagliabue et al., 2012) allow us to evaluate the performance of the model in terms of agreement to observations. The model is also compared to the previous model version of Keller et al. (2012) to identify the changes that result from including a dynamic iron cycle.

\subsection{The iron cycle}

The new model with a dynamic iron cycle allows us to provide an estimate of global marine iron fluxes between major biogeochemical pools (Fig. 3). With the deposition forcing from Luo et al. (2008) the atmospheric iron deposition is

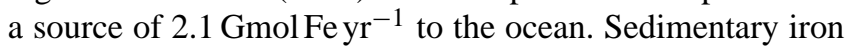
release is one order of magnitude higher than iron deposition on the global scale, confirming the important role of the sediment in supplying iron to the ocean as already suggested by prior studies (Moore and Braucher, 2008; Tagliabue et al., 2009). The sediment release of $18.8 \mathrm{Gmol} \mathrm{yr}^{-1}$ in our model is however still smaller than the $32.5 \mathrm{Gmol} \mathrm{yr}^{-1}$ of Misumi et al. (2014). Sixty three percent of the iron that is taken up by phytoplankton is recycled back to the dissolved iron pool. This compares well with observations of a large proportion of recycled to new iron sources (Boyd and Ellwood, 2010). The largest simulated flux is scavenging, which is even slightly larger than the remineralization of iron. Although some of the parameters are poorly constrained and, hence, there is some uncertainty in the magnitude of the fluxes, these results emphasize the difference between the iron cycle and macronutrient cycles since the residence time of iron in the ocean as computed from global inventory divided by global iron supply, which results to approximately 38 years here, is orders of magnitude shorter than the millennial residence timescales of 

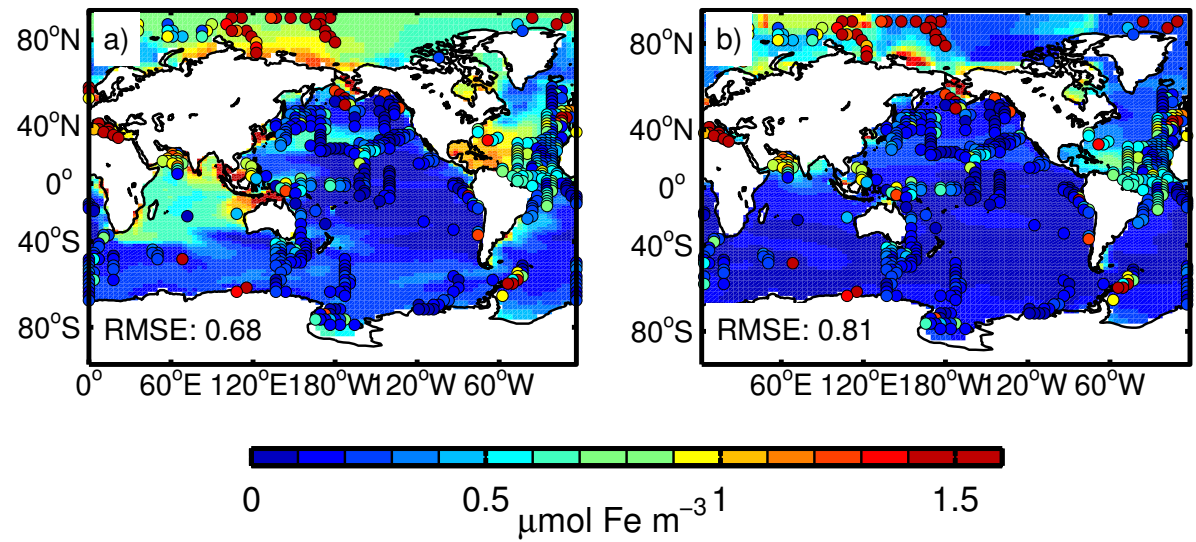

Figure 4. Annual mean surface iron concentrations (a) as simulated with the new model and (b) from the iron concentration mask used in the previous model version from Galbraith et al. (2010). Observations compiled by Tagliabue et al. (2012) are averaged over the first $50 \mathrm{~m}$ and plotted as colored circles on top.

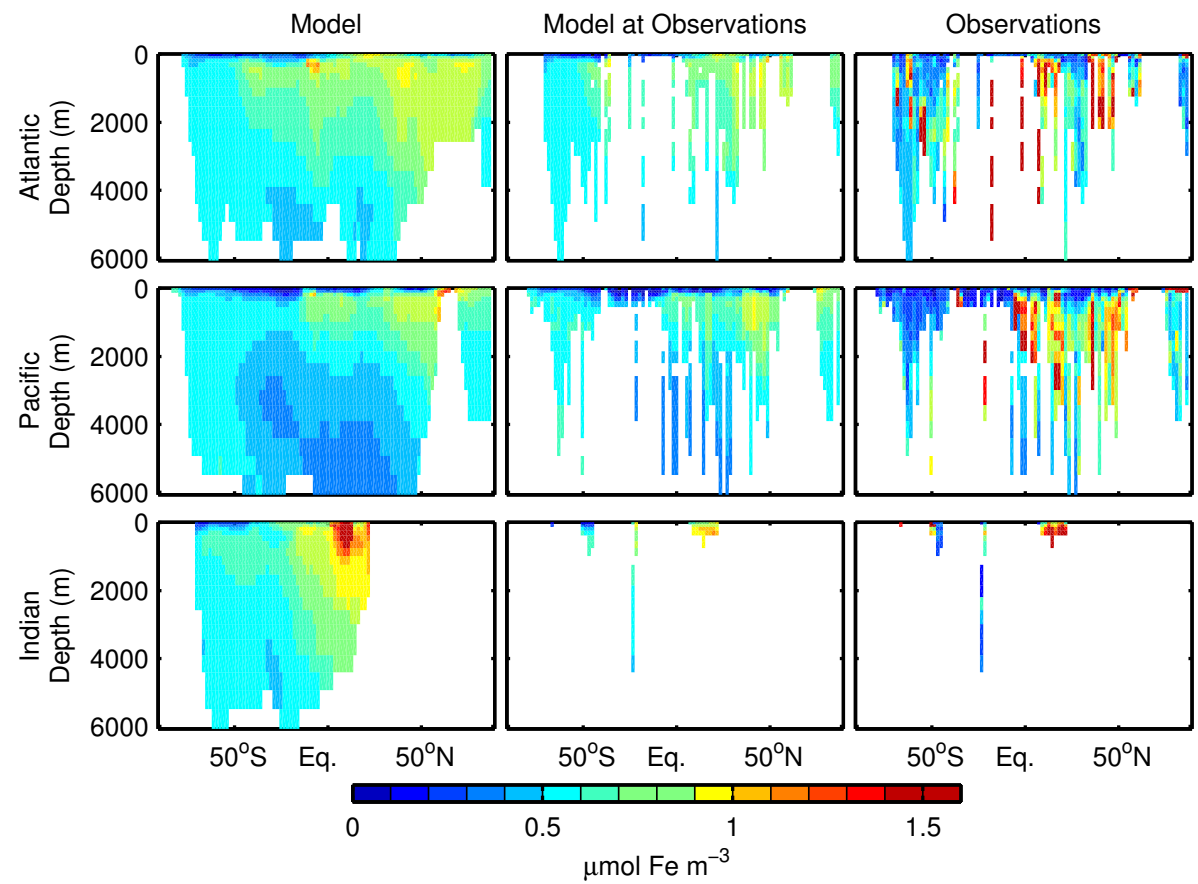

Figure 5. Zonal annual mean iron concentrations as simulated with the model (left column), model results averaged only at the locations of the observations (Tagliabue et al., 2012) (middle column) and observations (right column) for the different ocean basins.

the macronutrients nitrogen or phosphorus (Wallmann, 2010; Somes et al., 2013). This indicates that iron concentrations must be strongly dependent on local or regional sources. Our estimate of the iron residence time is within the range of other estimates of 12 years (Moore and Braucher, 2008) and 100 to 200 years (Boyd and Ellwood, 2010). The short residence time illustrates the potentially large leverage that changes in the Fe supply could have on marine biogeochemical cycles.

In comparison to the iron concentration mask used in the previous model version, the dynamically simulated surface iron concentrations in the new model are generally higher (Fig. 4). The average surface iron concentrations are $0.19 \mathrm{nM}$ for the concentration mask and $0.41 \mathrm{nM}$ for the new model. This is due to the higher stability constant of iron ligand complexes of $\log (K \mathrm{FeL})=11.5$ here compared to the values of 9.8 to 10.8 used in the model of Galbraith et al. (2010), from which the iron mask in Keller et al. (2012) had been taken. Our choice is more in line with recent observational estimates of $\log (K \mathrm{FeL})$ being in the range of 11-12 (Gledhill and Buck, 2012). An additional factor could be the linear dependence of inorganic scavenging on free iron concentrations in 


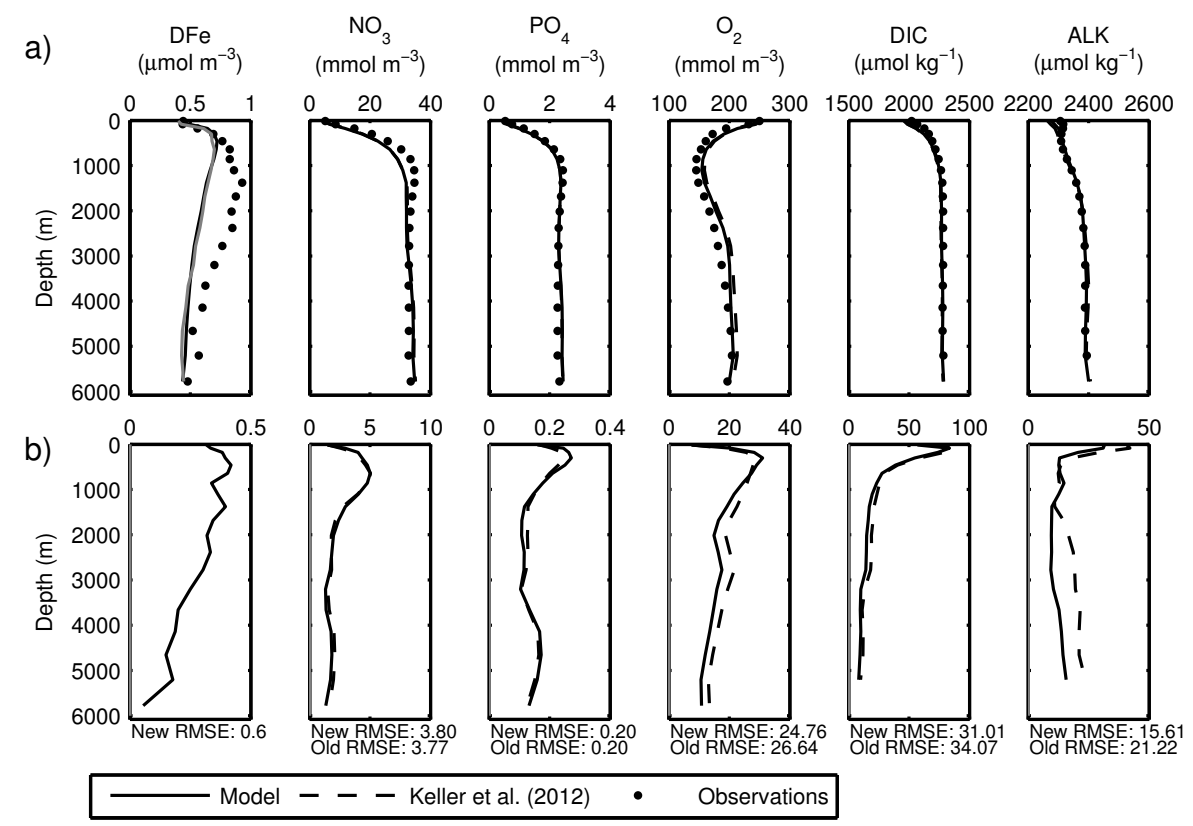

Figure 6. Vertical profiles comparing dissolved iron (DFe), nitrate $\left(\mathrm{NO}_{3}\right)$, phosphate $\left(\mathrm{PO}_{4}\right)$, oxygen $\left(\mathrm{O}_{2}\right)$, dissolved inorganic carbon $(\mathrm{DIC})$ and alkalinity (ALK) with observations from Tagliabue et al. (2012), the World Ocean Atlas 2009 and GLODAP (a) and vertical profiles of the horizontally averaged absolute differences between model and the observations (b). The gray line in the profile of dissolved iron is the horizontal average of simulated iron concentrations at the locations of the observations. The global root mean square errors (RMSE) relative to the observations are given below the respective panels in (b).

the model presented here (cf. Eq. 23) which differs from the scaled (to the power of 1.5) inorganic scavenging of free iron in the model of Galbraith et al. (2010). Since our new formulation results in less scavenging the surface iron concentrations are slightly overestimated in the subtropical North Pacific, the tropical Atlantic and possibly the Indian Ocean as well as the Arctic Ocean. However, the global root mean square error (RMSE), relative to observed surface iron concentrations (Tagliabue et al., 2012), decreases from 0.81 to $0.69 \mathrm{nM}$ when compared to the surface iron concentrations of the iron concentration mask used by Keller et al. (2012), e.g., the regridded results of the BLING model (Galbraith et al., 2010).

The simulated zonal mean iron concentrations reveal that the iron concentrations in the Southern Ocean are probably a little too high, particular in the Pacific (Fig. 5). The average simulated concentration in the Southern Ocean is $0.53 \mathrm{nM}$ and the observed value $0.56 \mathrm{nM}$, but in the Pacific sector the average simulated concentration is $0.56 \mathrm{nM}$ opposed to the observed $0.33 \mathrm{nM}$. However, the model does capture the high iron concentrations that have been observed in the northern Indian Ocean, as well as elevated iron concentrations in the North Pacific and North Atlantic. The highest observed dissolved iron concentrations of up to $1.5 \mathrm{nM}$ cannot be represented by the model because of the globally constant ligand concentration of $1 \mathrm{nM}$ which is probably too low in the regions of high iron concentrations (Gledhill and Buck, 2012).
The deviation of the profile of dissolved iron to the observations (Fig. 6) could be due to the constant and maybe too low ligand concentration assumed in the model and supports the notion that there is still no comprehensive understanding of sources and sinks of ligands although some promising approaches are emerging (Tagliabue and Völker, 2011; Misumi et al., 2013; Völker and Tagliabue, 2015). The observations also indicate that the simulated ferricline should be deeper than the nutricline (Fig. 6) (Tagliabue et al., 2014b). The other model tracers shown in Fig. 6 are discussed in the next section.

Simulated surface iron concentration show a seasonal variability that appears somewhat smaller than can be inferred from the available data (Fig. 7). In the Northern Hemisphere simulated iron concentrations between 40 and $60^{\circ} \mathrm{N}$ start to get depleted in April. This is associated with the spring and summer bloom in the Northern Hemisphere. At the same time iron concentrations in the Southern Ocean start to increase showing that, as also stated by Tagliabue et al. (2014b), supply of iron to the surface from the deeper ocean during austral winter is an important source of iron.

In summary, the new dynamic iron cycle model allows identification of the important fluxes between the iron pools, indicates that more research is needed on ligand dynamics and shows a clear improvement over the iron concentration masking approach that was used previously with UVic. In comparison to the model by Misumi et al. (2013), who also 

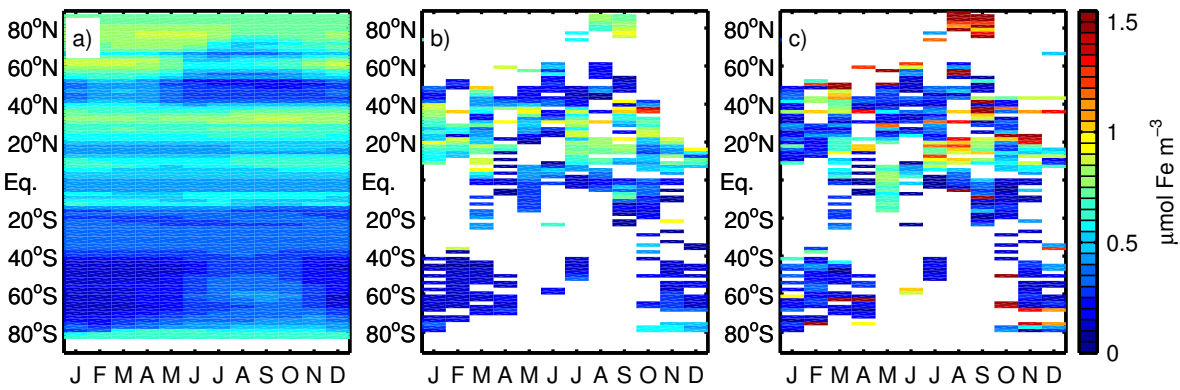

Figure 7. Zonal mean iron concentrations at the ocean surface plotted over time (Hovmöller diagram) as simulated with the model (a), model results averaged only at the locations of the observations (Tagliabue et al., 2012) (b) and the observations (c).
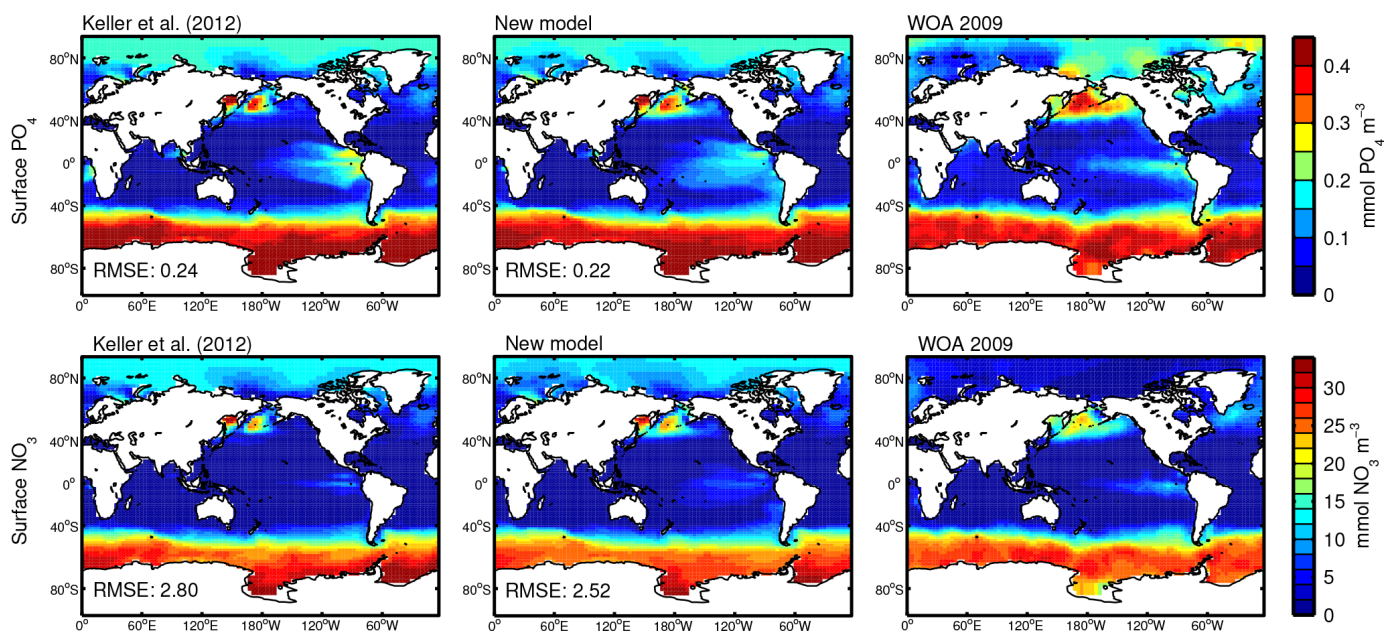

Figure 8. Annual mean surface phosphate (first row) and nitrate concentrations (second row) for the model by Keller et al. (2012) and the new model in comparison to observations from the World Ocean Atlas 2009 (WOA, 2009) (Garcia et al., 2010b).

compare their simulated iron concentrations to the full data set by Tagliabue et al. (2012) and calculated a RMSE of $0.78 \mathrm{nM}$ at the surface $(0-200 \mathrm{~m})$ and $0.86 \mathrm{nM}$ in the deep (200-5000 m) ocean, we get lower RMSEs of $0.58 \mathrm{nM}$ at the surface $(0-240 \mathrm{~m})$ and $0.61 \mathrm{nM}$ for the deep $(240-5000 \mathrm{~m})$ ocean.

One difficulty that we faced in evaluation of our results is that the observations of iron concentrations are still sparse and show high variability. The observed concentrations in the Southern Ocean are biased towards concentrations in the austral summer due to easier sampling at that time of the year (Tagliabue et al., 2012). Other limitations also have to be noted. Some regions are only poorly covered as for example the open Indian Ocean. Calculating root mean square errors and averaging over regions or depths will thus be biased towards strongly sampled regions. Different filter pore sizes of 0.2 to $0.4 \mu \mathrm{m}$ during the measurements include different proportions of colloidal and soluble iron and produce some uncertainty in the dissolved iron observations. Additionally, the observations cover a long time span with different measurement techniques which reduces systematic bias but also adds to the uncertainty (Tagliabue et al., 2012). However, the database of dissolved iron observations is the best possibility to evaluate model results and the increasing number of measurements are highly valuable for the validation of models of the iron cycle and will improve this possibility in the future.

\subsection{Biogeochemical validation}

Having a dynamic iron cycle induces changes in all other simulated biogeochemical properties. Here we compare the biogeochemical results of these new simulations to the observations and previous model and discuss the reasons for them.

In comparison to the previous model version, surface $\mathrm{PO}_{4}$ and $\mathrm{NO}_{3}$ in the Southern Ocean are slightly lower (by on average 0.05 and $1.3 \mathrm{mmol} \mathrm{m}^{-3}$, respectively) due to the higher iron concentrations and reduced Fe limitation (Fig. 8). In the equatorial Pacific, the $\mathrm{PO}_{4}$ concentrations are higher in the subtropical gyres, which are the regions where iron concentrations are smaller than $0.1 \mathrm{nM}$ (Fig. 4). This indicates that iron limitation might be too strong there. A further reason could be the not well-resolved equatorial current system 

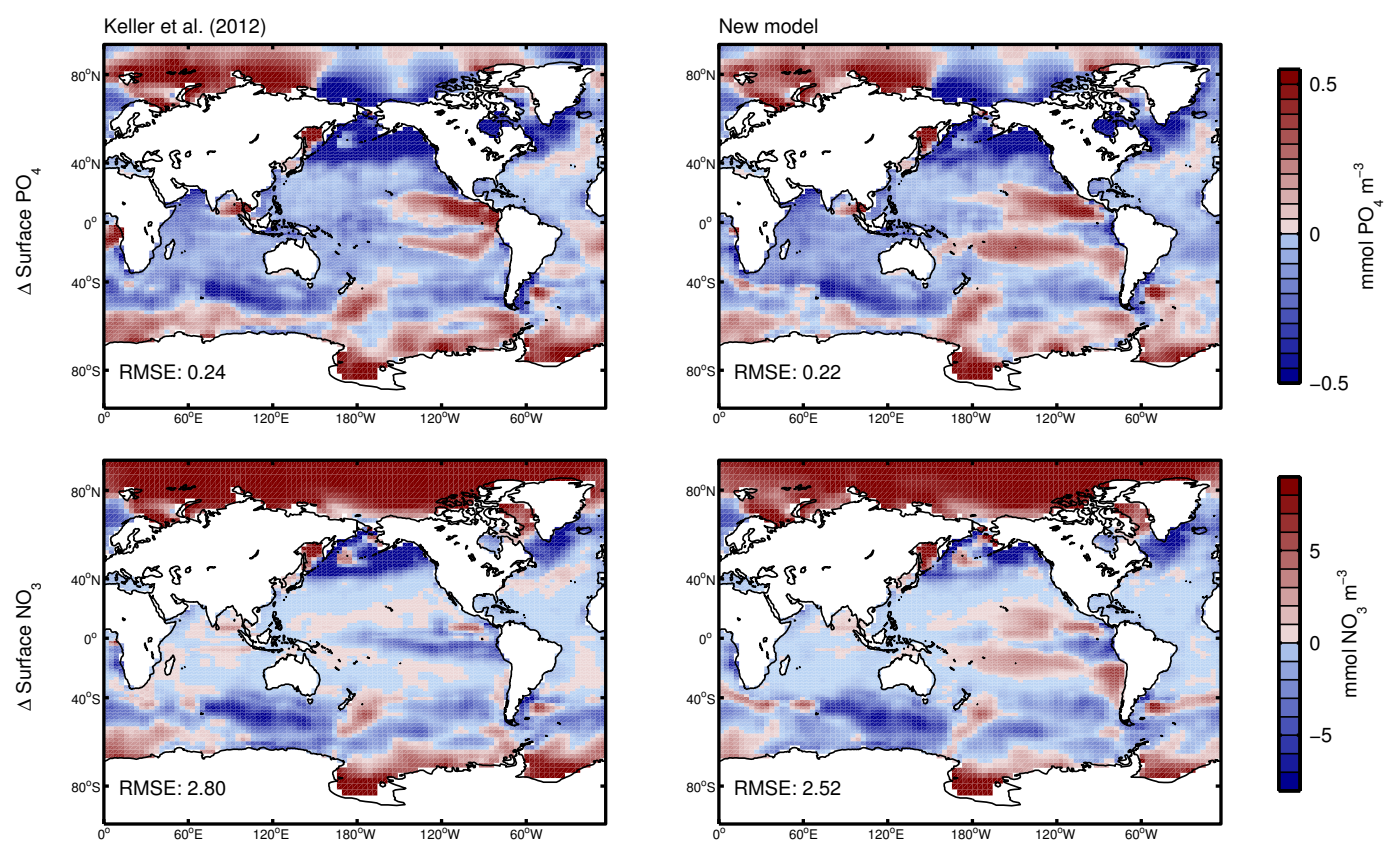

Figure 9. Difference between the annual mean surface WOA09 phosphate (first row) and nitrate observations (second row) and the values simulated with the model by Keller et al. (2012) and the new model.
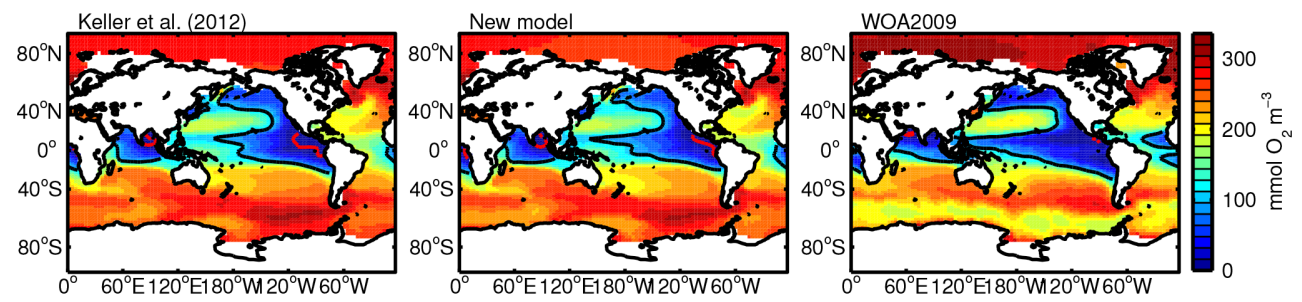

Figure 10. Annual mean oxygen concentrations at $450 \mathrm{~m}$ depth for the model by Keller et al. (2012) and the new model in comparison to observations from the World Ocean Atlas 2009 (WOA, 2009) (Garcia et al., 2010a). The black contour line is located at concentrations of $100 \mathrm{mmolO}_{2} \mathrm{~m}^{-3}$, the red contour line is located at concentrations of $5 \mathrm{mmolO}_{2} \mathrm{~m}^{-3}$.

(Getzlaff and Dietze, 2013). However, the overestimation of phosphate concentrations in the tropical Pacific seen in the previous version is reduced and $\mathrm{PO}_{4}$ and $\mathrm{NO}_{3}$ are also more in agreement with observations in the North Pacific (Fig. 9). In total, surface $\mathrm{PO}_{4}$ and $\mathrm{NO}_{3}$ RMSEs reduce by $0.02 \mathrm{mmol} \mathrm{PO}_{4} \mathrm{~m}^{-3}$ and $0.28 \mathrm{mmolNO}_{3} \mathrm{~m}^{-3}$ with the new version.

Changes in the surface nutrient limitation and hence productivity, influence oxygen concentrations via changes in the export of sinking organic matter to the deeper ocean and the subsequent oxygen consumption during remineralization. A common mismatch between observations and simulation results in models with a coarse resolution is that high nutrient concentrations are simulated in the eastern tropical Pacific and subsequently cause large oxygen minimum zones (OMZs), i.e. volumes of low oxygen waters $\left(<5 \mathrm{mmol} \mathrm{m}^{-3}\right)$, to be formed at intermediate depths as a result of processes that have been termed "nutrient trapping" (Najjar et al.,
1992; Dietze and Loeptien, 2013; Getzlaff and Dietze, 2013). With the new model the area of the OMZ in the eastern tropical Pacific at $450 \mathrm{~m}$ depth is reduced while low oxygen concentrations reach further into the western Pacific (Fig. 10). This is more in agreement with observations of low oxygen concentrations. The relatively low oxygen concentrations of around $190 \mathrm{mmol} \mathrm{m}^{-3}$ in some places of the Southern Ocean and the OMZ in the Indian Ocean can still not be represented by the model. The OMZ is located in the Bay of Bengal instead of the Arabian Sea in both model versions. This is a common model error (Moore and Doney, 2007) and a possible reason is the coarse resolution of these models which might not be able to realistically simulate Indian Ocean currents and the transport of nutrients and oxygen. However, in total, also the global oxygen concentrations have a slightly smaller error than in the previous model (Fig. 6).

The global net primary production (NPP) in the ocean is calculated to be $55 \mathrm{PgCyr}^{-1}$ in the new model while it 

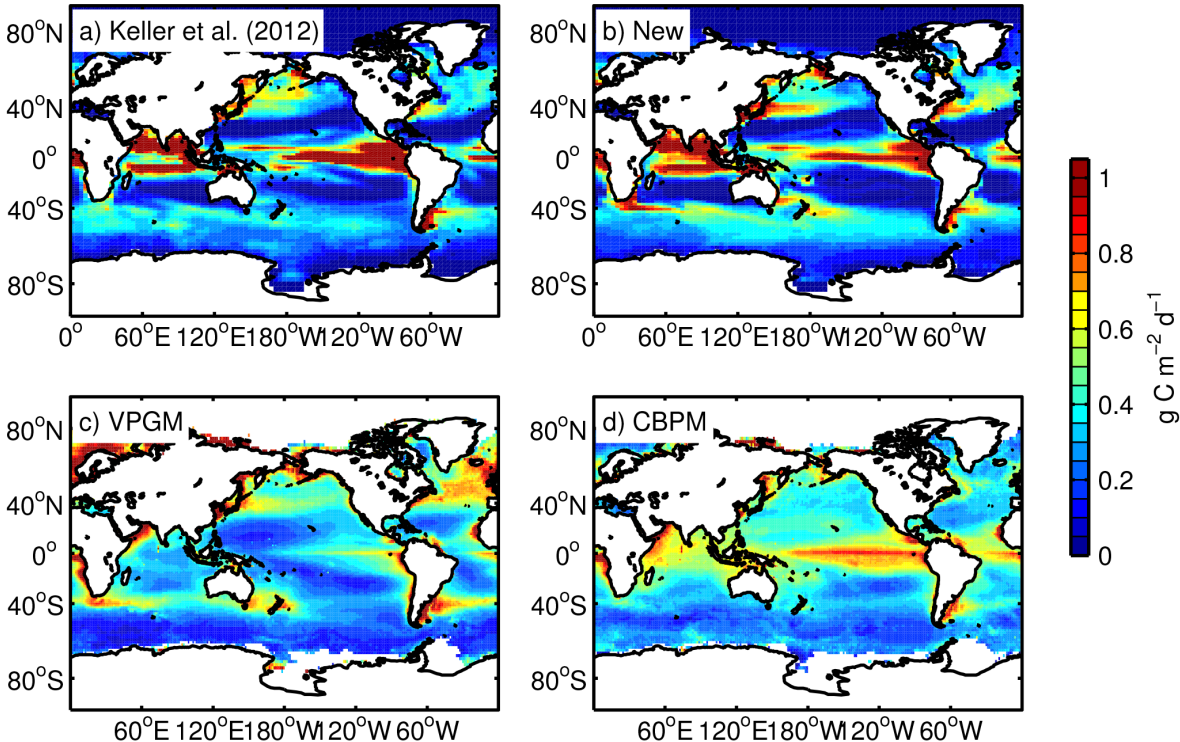

Figure 11. Marine vertically integrated annual mean net primary production for (a) the model by Keller et al. (2012), (b) the new model with the dynamic iron cycle, (c) the vertically generalized production model (VPGM) by Behrenfeld and Falkowski (1997), and (d) the carbon-based productivity model (CBPM) by Westberry et al. (2008).
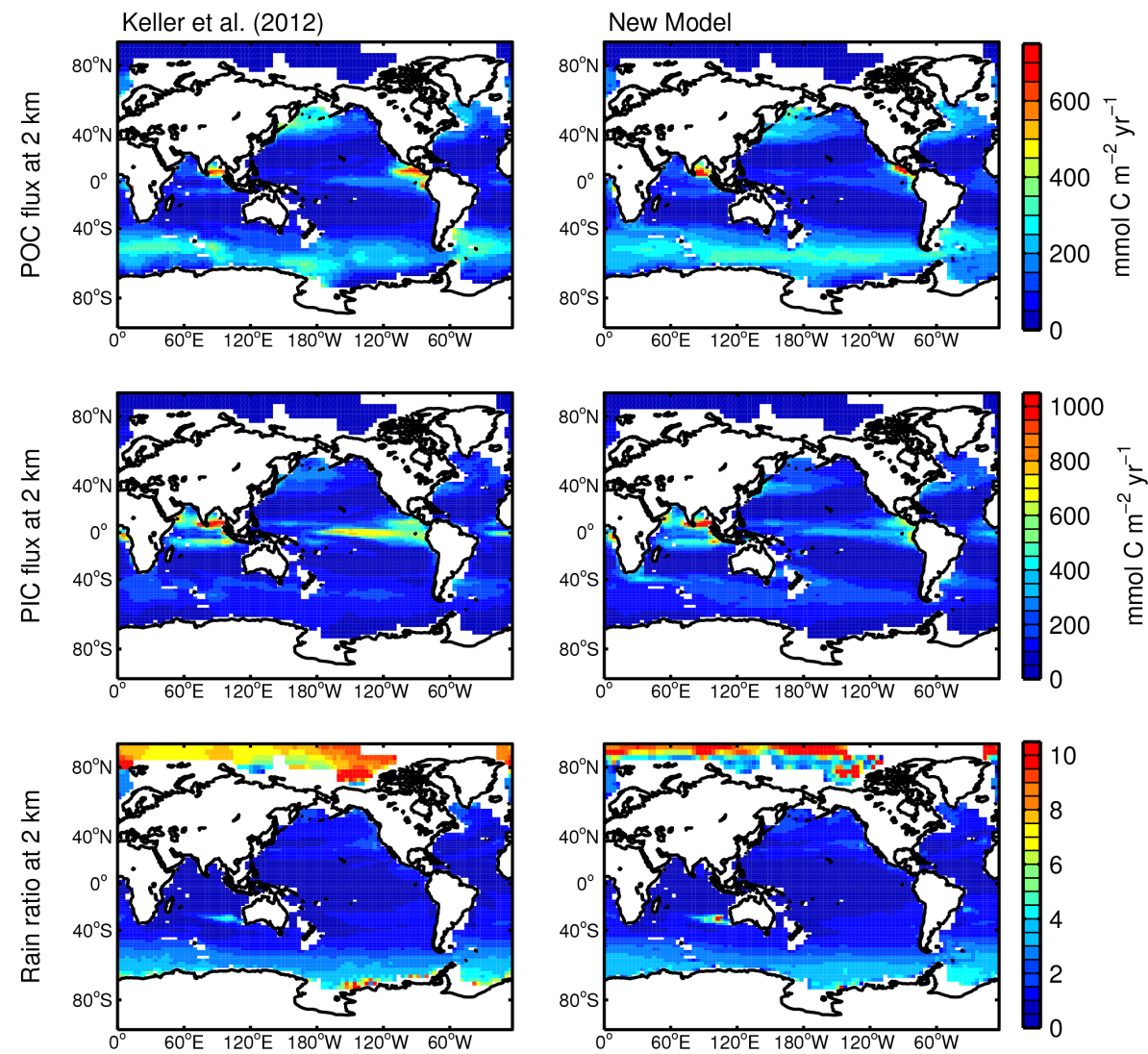

Figure 12. Annual fluxes of POC and PIC at $2 \mathrm{~km}$ and the rain ratio as simulated with the model by Keller et al. (2012) (left column) and with the new model (right column). 


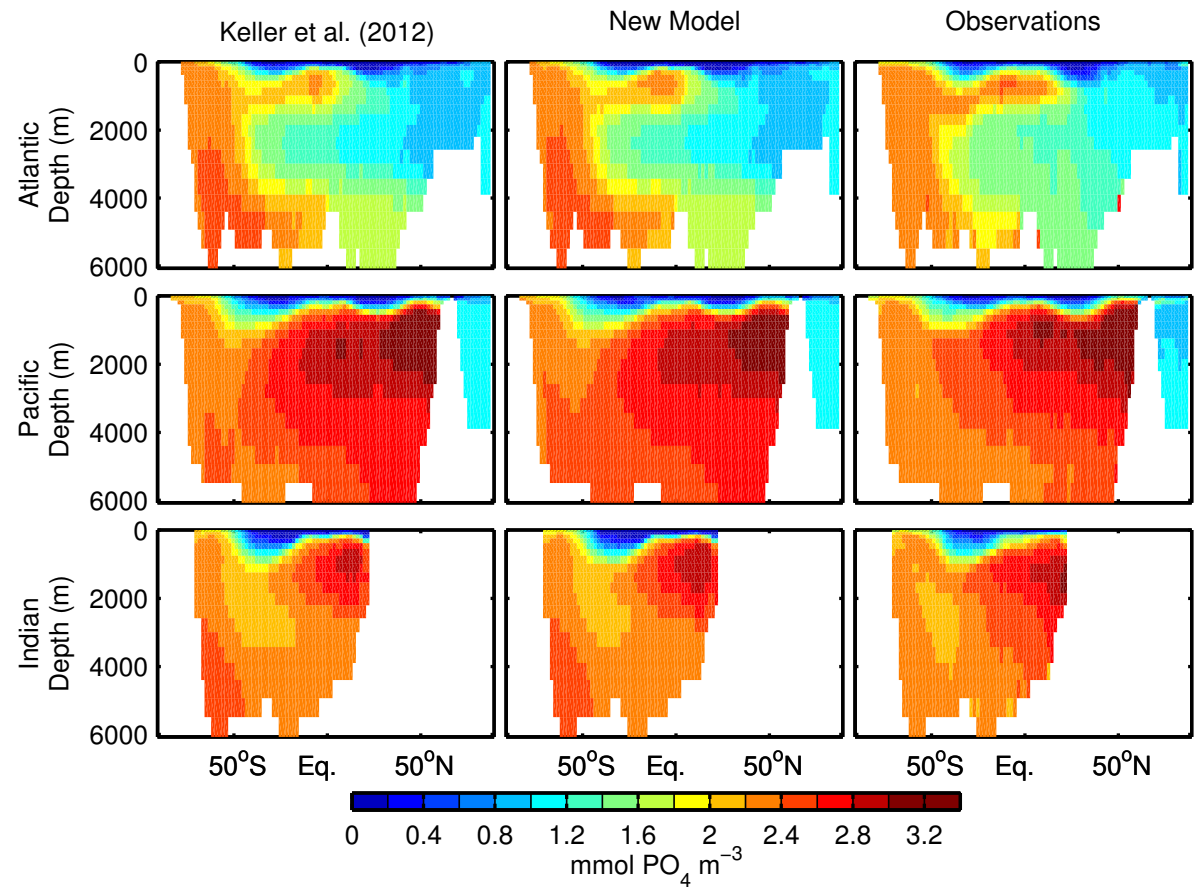

Figure 13. Zonal annual mean phosphate concentrations as simulated with the model by Keller et al. (2012) (left column) and the new model (middle column) in comparison to observations from the World Ocean Atlas 2009 (WOA, 2009) (Garcia et al., 2010b) (right column) for the different ocean basins.

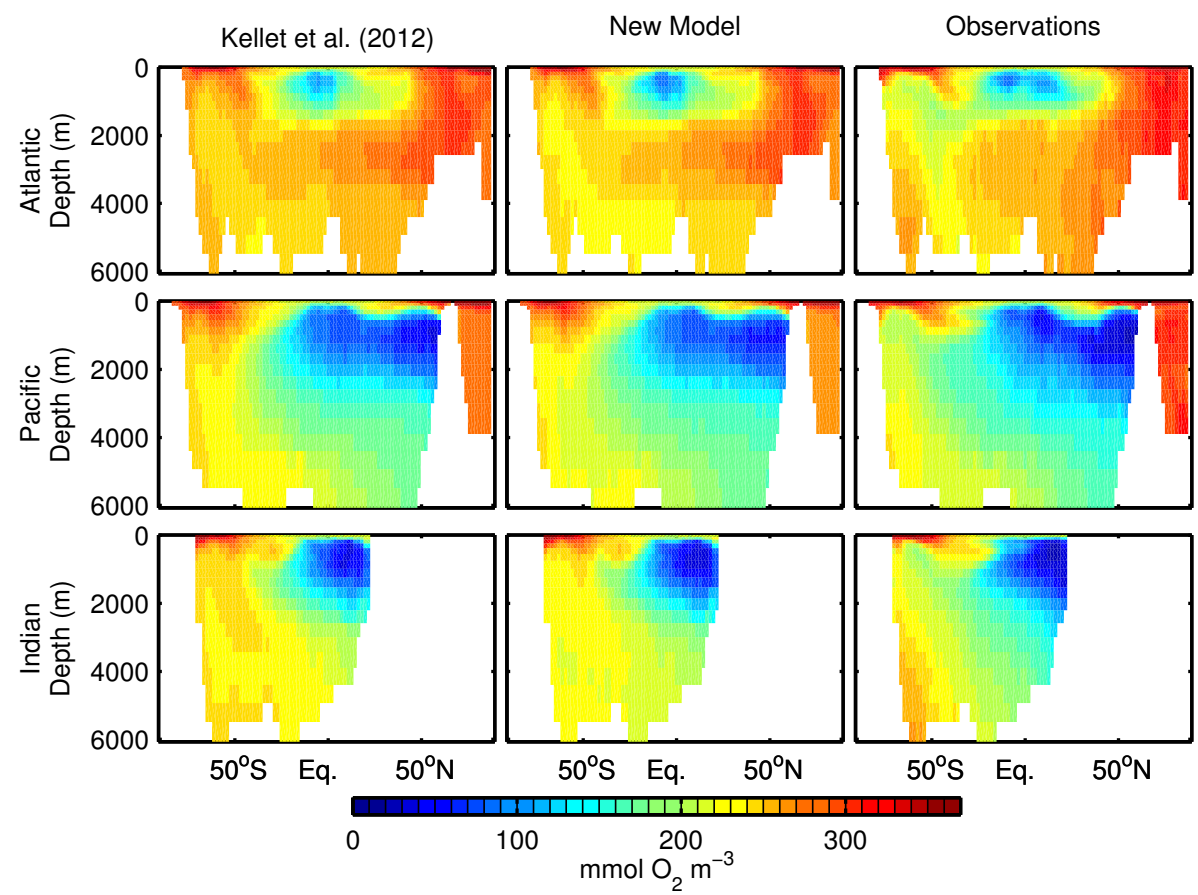

Figure 14. Zonal annual mean oxygen concentrations as simulated with the model by Keller et al. (2012) (left column) and the new model (middle column) in comparison to observations from the World Ocean Atlas 2009 (WOA, 2009) (Garcia et al., 2010a) (right column) for the different ocean basins.

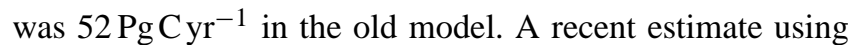
both, observations and models, is in the same range, stat- ing that $56 \mathrm{PgC} \mathrm{Cr}^{-1}$ is the most probable value for global NPP (Buitenhuis et al., 2013). Spatially, the NPP in the new 


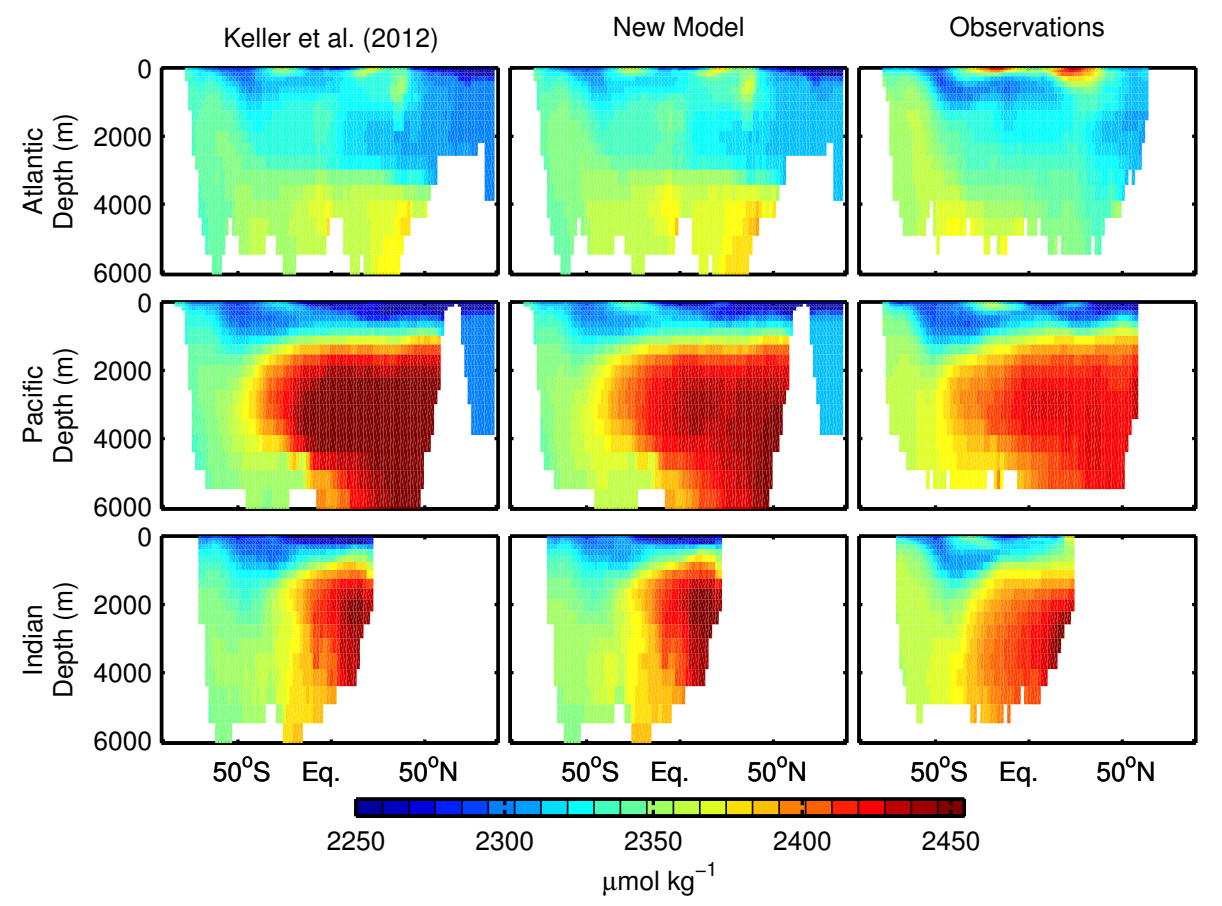

Figure 15. Zonal annual mean alkalinity as simulated with the model by Keller et al. (2012) (left column) and the new model (middle column) in comparison to observations from GLODAP (right column) for the different ocean basins.

model deviates from the NPP in the previous model mostly in that the production is more centered on the equator in the Pacific Ocean and less production occurs in the eastern tropical Pacific (Fig. 11). The new model also shows higher production downstream of the southern tips of the continents in the Southern Ocean, such as South America, Africa and Australia. Although generally in comparison to the satellitebased observational estimates coastal production seems still to be underestimated and open-ocean production overestimated (Keller et al., 2012); the production in the equatorial Pacific and eastern tropical Pacific are now more similar to the observations.

These changes in productivity, relative to the old model, affect the simulated biological pump. Lower NPP in the equatorial and eastern tropical Pacific is mirrored in the export of organic and inorganic matter (particulate organic carbon (POC) and particulate inorganic carbon (PIC) fluxes) at $2 \mathrm{~km}$, in contrast to the higher export with the old model (Fig. 12a). Export in the North Pacific also decreases, although it is slightly higher off the coast of Japan. In contrast, export in the Southern Ocean is higher. The change of the PIC flux from the old to the new model is similar to that of the POC flux with decreases in the equatorial and eastern tropical Pacific, North Pacific and increases in the Southern Ocean (Fig. 12b). Accordingly, the rain ratio does not change substantially except for the Arctic Sea but POC and PIC fluxes are very low there so that the ratio is very sensitive to small changes and thus unimportant in a global context (Fig. 12c).
The higher export in the Southern Ocean with respect to the old version also increases deep phosphate concentrations in the Southern Ocean (Figs. 13, S2). Apart from this Southern Ocean increase, zonally averaged phosphate concentrations are very similar to the old model. The global difference of $\mathrm{NO}_{3}$ to the old version is similar to that of $\mathrm{PO}_{4}$ because the same mechanisms apply except for $\mathrm{N}$ fixation and denitrification which are discussed later.

The increased export production in the Southern Ocean with the new model leads to more remineralization at the subsurface ocean and thus reduces oxygen concentrations (Fig. 14). This is more in line with observations as also shown by difference plots of both models to observations in the Supplementary Fig. S3. However, the observed two oxygen minima in the Atlantic Ocean directly south and north of the equator cannot be represented by the old nor the new model, presumably because of physical limitations of the model. A better representation can be achieved by adjusting the isopycnal diffusivity as in Getzlaff and Dietze (2013) and will be implemented in a future version. Globally, the RMSE of the oxygen concentrations is reduced from $26.64 \mathrm{mmolO}_{2} \mathrm{~m}^{-3}$ with the old model to $24.77 \mathrm{mmolO}_{2} \mathrm{~m}^{-3}$ with the new model. The improvement also stems from the oxygen concentrations at depths of 2000 to $3000 \mathrm{~m}$ in the subtropical Atlantic that are lower in comparison to the old model and thus again closer to observed values. 
The changes in zonal mean ALK are also closely linked to changes in export production, but the improvements in ALK, in comparison to the observations, take place in different regions than for oxygen (Fig. 15, S4). The lower export production in the equatorial and North Pacific lowers ALK at intermediate depths, which thereby increases the agreement between the simulation results and the observations substantially. The improvements in ALK and oxygen are also visible in the globally averaged depth profiles of the model tracers in Fig. 6. Except for ALK and oxygen, the old and the new model look very similar. Differences between the simulation results and the observations, however, tend to be smaller with the new model (Fig. 6b).

The iron limitation of diazotrophs is suggested to be a major control of nitrogen fixation and thus on an important source of new oceanic nitrogen (Mills et al., 2004). With the new dynamic iron cycle simulated nitrogen fixation not only shifts more to the western tropical Pacific but also increases near the coast of the eastern tropical Pacific, where deeper in the water column denitrification is taking place (Fig. 16). The vicious cycle hypothesis by Landolfi et al. (2013) states that spatially coupled nitrogen fixation and denitrification can lead to substantial loss of nitrogen when enhanced export production by the fixed nitrogen triggers oxygen consumption in deeper waters and thus increases denitrification which in turn increases nitrogen deficiency in upwelling water to the surface creating a niche for diazotrophs. Iron limitation at the surface was discussed as a mechanism that interrupts this feedback by shifting the nitrogen fixation to regions of sufficient iron concentrations away from the region of low oxygen concentrations and denitrification. However, the new model shows that near the coast, the spatial coupling of nitrogen fixation and denitrification can take place when the shallow sediments are a strong source of iron sufficient to sustain nitrogen fixation (cf. Fig. 2b). Elevated coastal iron concentrations may thus allow the feedback between nitrogen fixation and denitrification to exist. Indeed, Fernandez et al. (2011) observe $\mathrm{N}$ fixation in the eastern tropical Pacific in the area of the OMZ but more observations are needed to decide whether this feedback occurs as indicated by our model.

\section{Model experiments}

Critical assumptions in modeling the iron cycle are associated with the external sources of iron to the water column, atmospheric iron deposition and sediment release and ligand concentrations (Tagliabue et al., 2014a). Here we show the results of sensitivity tests of the globally constant ligand concentration, which is used to parameterize ligand-iron interactions, and evaluate the importance of assuming the spatially variable solubility of iron in dust and the water column depth of sedimentary iron release. The importance of assuming the spatially variable solubility of iron in dust and the water column depth of sedimentary iron release are tested for various globally fixed ligand concentrations. We also test the influence of a temperature dependence of sedimentary iron release and perform a climate warming simulation. All experiments are listed in Table 2. All experiments except the climate warming simulation are run for 1000 years and the drift in average surface $\mathrm{PO}_{4}$ during the last 100 years is less than $1.2 \mu \mathrm{mol} \mathrm{PO}_{4} \mathrm{~m}^{-3}$.

Ligand concentrations strongly control bioavailable iron concentrations (Gledhill and Buck, 2012). We thus examined the influence of varying the globally constant ligand concentrations between values of 0.6 and $1.2 \mathrm{nM}$ on dissolved iron concentrations (Fig. 17). The globally averaged vertical profile of dissolved iron is strongly influenced by this variation at all depths and basically shifted to lower values for low ligand concentrations and higher values for high ligand concentrations while the shape of the curve is hardly affected. The vertical profiles of the absolute mean deviation of simulated to observed dissolved iron concentrations reveal that the chosen concentration of $1 \mathrm{nM}$ is a compromise between good representation at the surface and in deeper waters. Also the global RMSE of simulated iron concentrations with a value of $0.6 \mathrm{nM}$ is lowest for a ligand concentration of $1 \mathrm{nM}$. Ligand concentrations of $0.6,0.8$ and $1.2 \mathrm{nM}$ lead to RMSE values of $0.69,0.64$ and $0.6 \mathrm{nM}$, respectively. While ligand concentrations of 0.6 or $0.8 \mathrm{nM}$ decrease the difference to the observations from the surface to around 600 to $800 \mathrm{~m}$, the deviation is increased below. On the other hand, if ligand concentrations equal $1.2 \mathrm{nM}$ everywhere, the deviation from observed iron concentrations is increased from the surface down to $1500 \mathrm{~m}$ and is decreased or similar to the control simulation with a $1 \mathrm{nM}$ ligand concentration below. For an improved agreement to the iron observations, lower ligand concentrations in the upper $1000 \mathrm{~m}$ would be required than below that depth, although one has to note that the low data coverage of the iron observations makes it difficult to draw robust conclusions. Völker and Tagliabue (2015) developed a model for the description of the global distribution of ligands in which they also have to assume strong ligand loss processes at the surface in order to achieve a good representation of the ligand and iron concentrations. Spatially, varying the ligand concentrations in our model leads to the strongest differences in dissolved iron concentrations in the Indian Ocean, the tropical and subtropical Atlantic and the subtropical North Pacific. In the other regions, iron limitation prevails, iron concentrations are already small and do not decrease much further with lower ligand concentrations. If ligand concentrations are increased in these iron limited regions, the additional bioavailable iron that is produced is readily taken up by phytoplankton so that the difference is small as well. Overall, the sensitivity of dissolved iron concentrations is very high (on average $\pm 0.27 \mathrm{nM}$ at the surface). Because of this strong sensitivity, better constraints on the source and sink processes of ligands are needed to create a comprehensive and computationally 
Table 2. Summary of the model experiments conducted with short name, description and the parameter value of the globally constant ligand concentration.

\begin{tabular}{lll}
\hline Experiment name & Description & Ligand concentration \\
\hline CTL & Control simulation configured as described in Sect. 2 & $1 \mathrm{nM}$ \\
LIG06 & The globally fixed ligand concentration parameter $\left(L_{\mathrm{T}}\right)$ is varied & $0.6 \mathrm{nM}$ \\
LIG08 & The globally fixed ligand concentration parameter $\left(L_{\mathrm{T}}\right)$ is varied & $0.8 \mathrm{nM}$ \\
LIG12 & The globally fixed ligand concentration parameter $\left(L_{\mathrm{T}}\right)$ is varied & $1.2 \mathrm{nM}$ \\
SOL08 & The solubility of iron in dust is set to a constant value of 1\% & $0.8 \mathrm{nM}$ \\
SOL10 & The solubility of iron in dust is set to a constant value of 1\% & $1 \mathrm{nM}$ \\
SOL12 & The solubility of iron in dust is set to a constant value of 1\% & $1.2 \mathrm{nM}$ \\
BAT08 & The subgrid-scale bathymetry is shut off & $0.8 \mathrm{nM}$ \\
BAT10 & The subgrid-scale bathymetry is shut off & $1 \mathrm{nM}$ \\
BAT12 & The subgrid-scale bathymetry is shut off & $1.2 \mathrm{nM}$ \\
TDEP & The temperature dependence of the sedimentary iron release is shut off & $1 \mathrm{nM}$ \\
CO ${ }_{2} E M I$ & Climate warming scenario with $\mathrm{CO}_{2}$ emissions following a RCP 8.5 scenario & $1 \mathrm{nM}$ \\
\hline
\end{tabular}
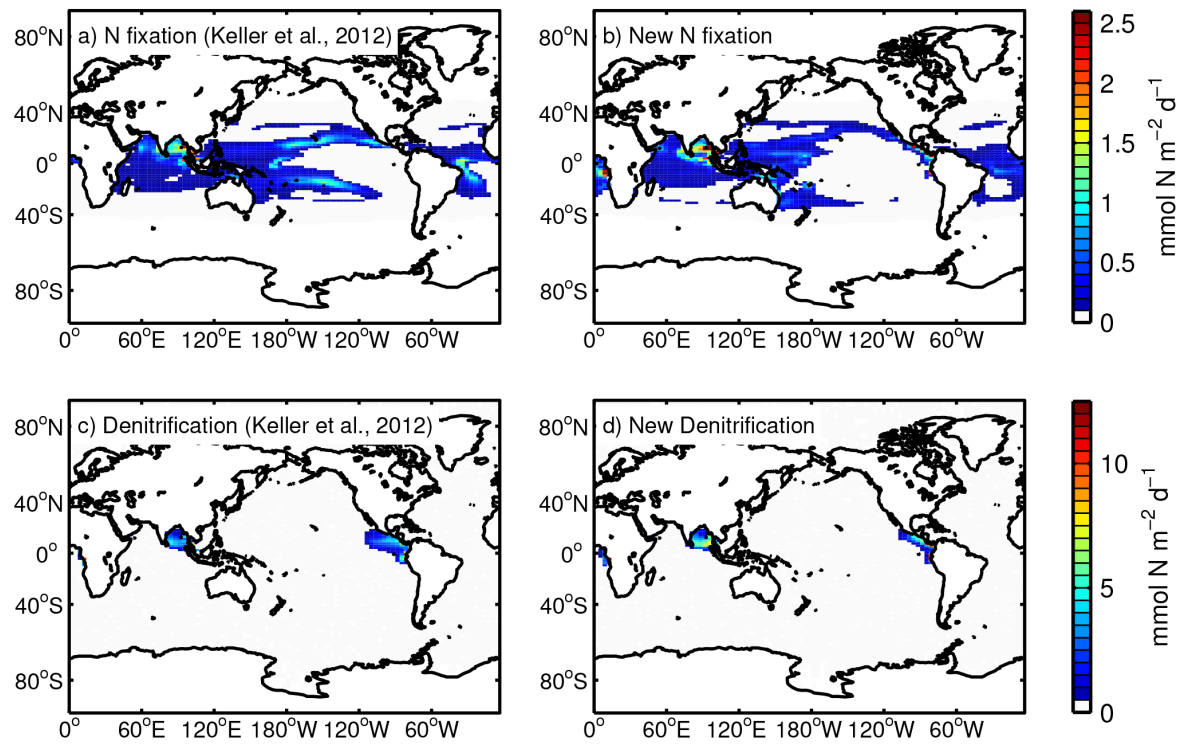

Figure 16. Annual mean nitrogen fixation with the model by Keller et al. (2012) (a) and the new model (b) and denitrification with the model by Keller et al. (2012) (c) and the new model (d). Values below $0.1 \mathrm{mmolN} \mathrm{m}^{-2} \mathrm{~d}^{-1}$ are not shown for (a) and (b) while values below $0.5 \mathrm{mmol} \mathrm{N} \mathrm{m}^{-2} \mathrm{~d}^{-1}$ are not shown for (c) and (d).

efficient representation of variable ligand concentrations in global ocean models.

Most previous modeling studies have assumed a constant solubility of iron in dust (Moore and Braucher, 2008; Tagliabue et al., 2014a; Nickelsen and Oschlies, 2015). However, observations show that the solubility of iron in dust can vary significantly and is generally lower in areas of high dust deposition and higher when dust deposition is low (Baker and Croot, 2010). Luo et al. (2008) tested several assumptions on how iron solubility could change during transport in the atmosphere and compared their simulated atmospheric iron deposition to observations of iron deposition. They found that assuming all iron that comes in contact with clouds is slowly converted to soluble iron and that particularly hematite is a source of soluble iron under acidic conditions results in the best agreement to observations. Their simulated iron deposition also reflects the observed trend of increased solubility at sites of low deposition. To test the importance of having variable solubility we performed a simulation in which iron solubility was set to a constant value of $1 \%$ (this is equal to the global average solubility of the standard model run which has variable solubility) and ran the experiment for 1000 years. We repeated this experiment with different globally constant ligand concentrations of $0.8 \mathrm{nM}$ (experiment SOL08) and $1.2 \mathrm{nM}$ (experiment SOL12) (cf. Table 2). The results are compared here to the results of the standard model simulation with variable solubility (CTL) and the runs from the ligand concentrations sensitivity experiments 

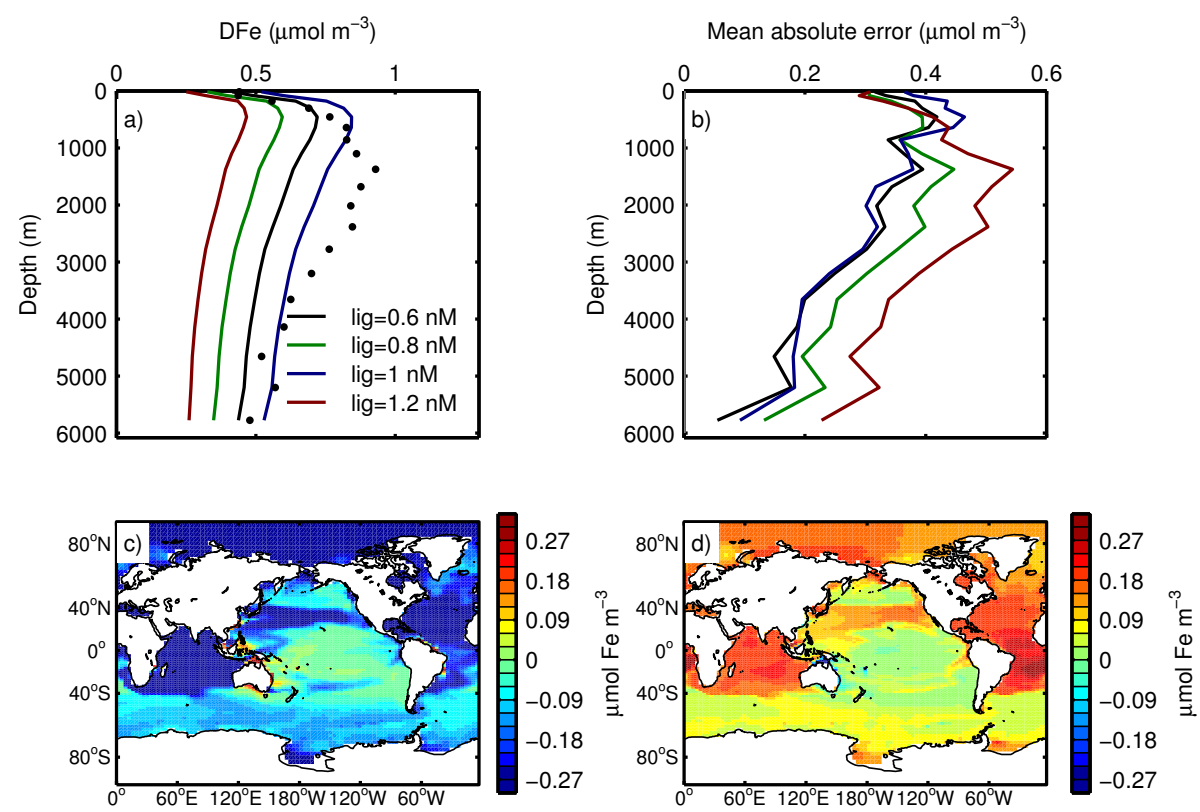

Figure 17. Impact of varying the globally constant ligand concentration on the globally averaged vertical profiles of dissolved iron (a), vertical profiles of the horizontally averaged absolute differences between model and the observations (b), difference between annual mean surface dissolved iron concentrations when ligands are set at constant values of lig $=0.6 \mathrm{nM}$ and lig $=1.0 \mathrm{nM}$ (c), difference between annual mean surface dissolved iron concentrations when ligands are set at constant values of lig $=1.2 \mathrm{nM}$ and lig $=1.0 \mathrm{nM}(\mathbf{d})$.
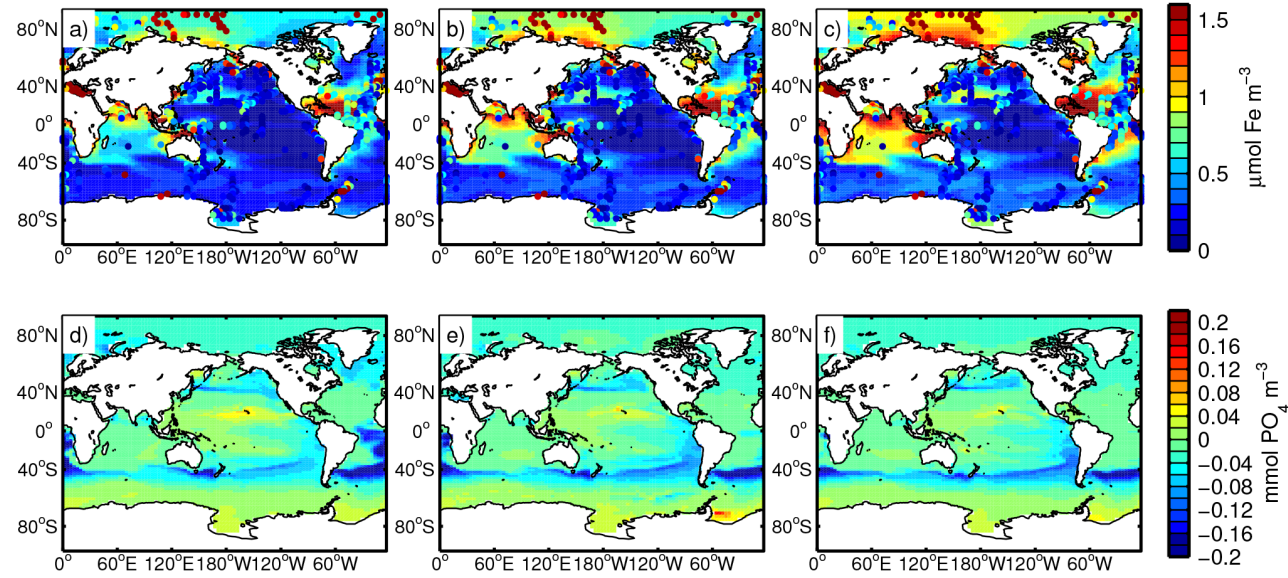

Figure 18. Impact of setting the iron solubility in dust to a constant value of $1 \%$. Annual mean simulated surface iron concentrations with observations compiled by Tagliabue et al. (2012) averaged over the first $50 \mathrm{~m}$ plotted as colored circles on top for experiment SOL08 are shown in (a), for SOL10 in (b) and for SOL12 in (c). The difference between the annual mean surface phosphate concentrations after 1000 years of experiment SOL08 and LIG08 are shown in (d), between SOL10 and LIG10 in (e) and between SOL12 and LIG12 in (f). The experiments are listed in Table 2.

LIG08 and LIG12. Although the integrated total iron deposition increases from 2.1 in CTL to $17.8 \mathrm{GmolFe} \mathrm{m}^{-2} \mathrm{yr}^{-1}$ in SOL01, the changes in surface iron concentrations are small (Figs. 18 and 4). As expected iron concentrations are higher at sites of high dust deposition $(+2 \mathrm{nM} \mathrm{Fe}$ in the tropical Atlantic and $+1 \mathrm{nM} \mathrm{Fe}$ in the Arabian Sea) and lower at low dust deposition $(-0.1 \mathrm{nM} \mathrm{Fe}$ in the tropical Pacific). In the SOL08 experiment with constant solubility and a ligand con- centration of $0.8 \mathrm{nM}$, a part of the increase in surface iron concentration in the high dust deposition areas is compensated by the lower ligand concentrations. In contrast, with a ligand concentration of $1.2 \mathrm{nM}$ the constant solubility leads to strong overestimation of surface iron concentrations.

Surface phosphate concentrations are essentially unaffected because the iron limited areas are still iron limited and regions in which iron deposition is high are not iron limited 

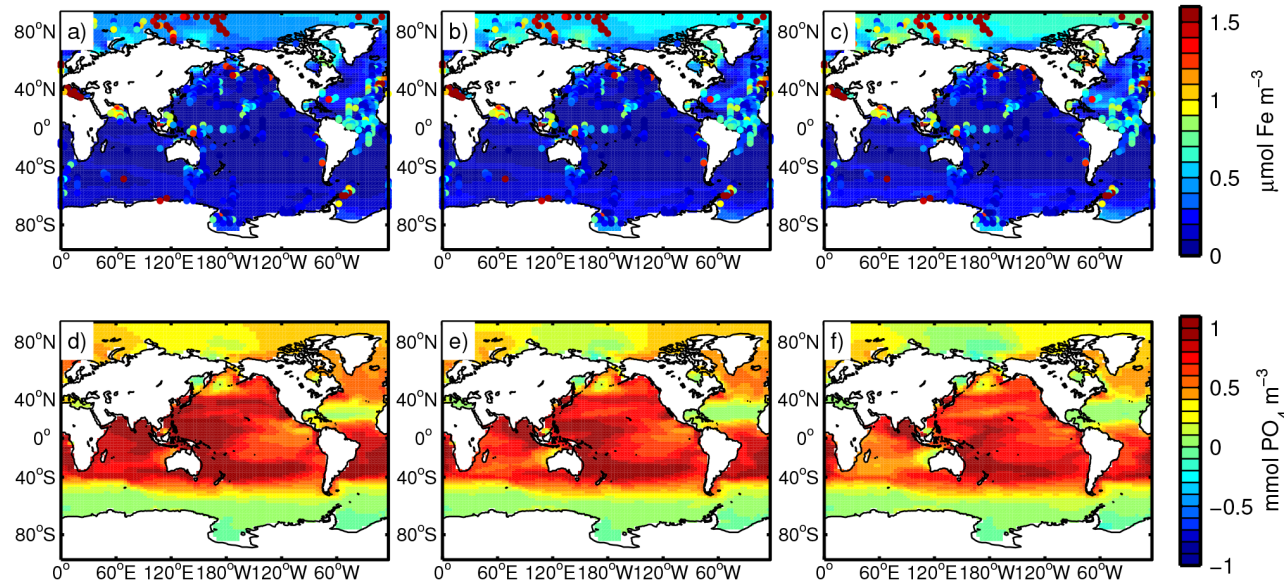

Figure 19. Impact of shutting of the subgrid-scale bathymetry after a 1000 year simulation. Annual mean simulated surface iron concentrations with observations compiled by Tagliabue et al. (2012) averaged over the first $50 \mathrm{~m}$ plotted as colored circles on top for experiment BAT08 are shown in (a), for BAT10 in (b) and for BAT12 in (c) (cf. Table 2). The difference between the annual mean surface phosphate concentrations after 1000 years of experiment BAT08 and LIG08 are shown in (d), between BAT10 and LIG10 in (e) and between BAT12 and LIG12 in (f). The experiments are listed in Table 2.

in both cases. The only exceptions are based on a slight increase of iron concentrations at the southern tips of Australia $(+0.3 \mathrm{nM})$ and South America (up to $+0.2 \mathrm{nM})$. These are the areas where surface phosphate concentrations decrease. The strongest effect of the consideration of the variable solubility can be seen in the RMSE of simulated surface iron concentrations. The RMSE increases from $0.68 \mathrm{nM}$ with variable solubility to $0.91 \mathrm{nM}$ with constant solubility. This result supports the observation of variable solubility of iron in dust and the approach of Luo et al. (2008) but a higher spatial coverage of iron observations is needed to verify this result.

To investigate how ligand concentrations influence the response to the change in the solubility of iron in dust, we compare the surface phosphate concentrations of the experiments SOL08 and SOL12 to the surface phosphate concentrations of the experiments LIG08 and LIG12 (Fig. 18d-f). For the higher ligand concentrations the difference in surface phosphate concentrations is even smaller than for the lower ligand concentrations. Higher iron concentrations in the control run buffer changes in the external supply since iron concentrations are generally higher and the change of iron concentrations relative to their background concentration is smaller. As suggested also by Tagliabue et al. (2014a) ligand concentrations can have a strong control on sensitivities to changes in dust deposition.

The sediment release of iron is a much larger source of iron to the ocean than dust deposition (Tagliabue et al., 2014a), but it is not clear how much iron released from the sediment reaches the surface ocean. One factor determining whether iron from the sediments reaches the surface ocean in coarse-resolution global ocean models is that the simulated bathymetry can deviate quiet strongly from the actual bathymetry. As in other models (Moore and Braucher, 2008;
Tagliabue et al., 2014a), we use a subgrid-scale bathymetry to correct the depth of the sedimentary iron release to that of a high-resolution data set of ocean depth. To test the importance of this depth correction, we turned the correction off in our second experiment and ran the model for 1000 years. This leads to much lower surface iron concentrations, more phytoplankton iron limitation (NPP decreases from 55 to $39 \mathrm{PgC} \mathrm{yr}^{-1}$ ) and an accumulation of macronutrients at the ocean surface (Fig. 19). Although the globally integrated release of iron from the sediment increases from $18.8 \mathrm{GmolFe} \mathrm{yr}^{-1}$ in the control run to $35.5 \mathrm{Gmol} \mathrm{Fe} \mathrm{yr}^{-1}$ in the experiment due to local feedbacks in the western Gulf of Mexico and north of Indonesia (Fig. 19a), iron in the experiment is released deeper and in regions that are not iron limited. This shows that iron released from the sediment is crucial for sustaining iron concentrations at the surface in iron limited regions and that the depth of iron release is an important factor to consider in coarse-resolution models. However, these results depend on the assumptions made for iron release from the sediment. The question whether sedimentary released iron reaches the surface is critical and observations show high uncertainties. At the study site of Elrod et al. (2004) with measurement depths ranging from 95 to $3710 \mathrm{~m}$ off of the California coast the amount of sedimentary released iron reaching the surface varies by 2.5 to $30 \%$. In a modeling study the efficiency of iron delivery from sediments to surface ocean waters can vary by $10-50 \%$ (Siedlecki et al., 2012) depending on frequent wind changes. Therefore, more research is needed on the fate of sedimentderived iron.

To test the influence of the globally constant ligand concentration parameter on the effect of shutting off the subgridscale bathymetry, we repeated the experiment with different 

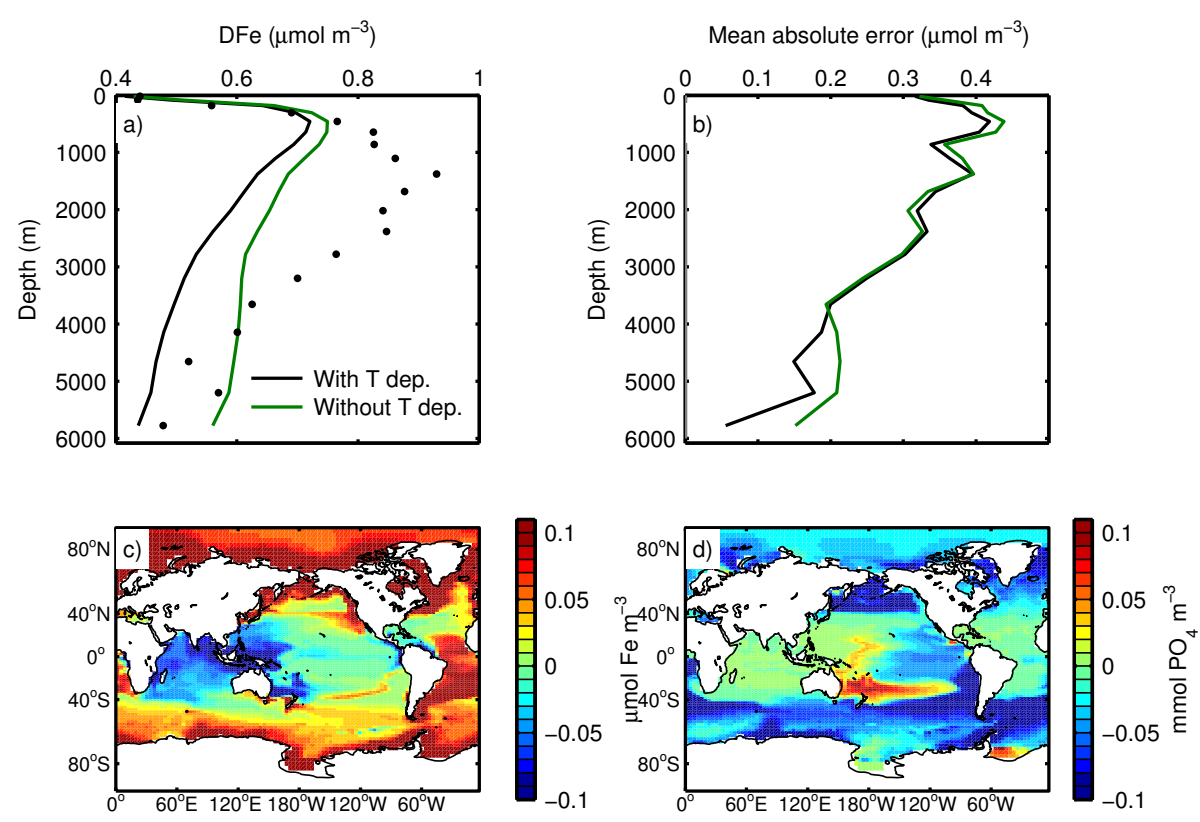

Figure 20. Influence of the temperature dependence ( $T$ dep.) of the benthic iron release. (a) Vertical profiles of globally averaged dissolved iron concentrations (DFe) with (black) and without (green) the temperature dependence. (b) Vertical profile of the averaged absolute deviation between simulated and observed DFe with (black) and without (green) the temperature dependence. (c) Difference in surface dissolved iron concentrations and (d) difference in surface phosphate concentrations between the simulations without and with the temperature dependence.

globally constant ligand concentrations of $0.8 \mathrm{nM}$ (experiment BAT08) and $1.2 \mathrm{nM}$ (experiment BAT12) (cf. Table 2). While iron concentrations are slightly higher with higher ligand concentrations (e.g. in the tropical Atlantic), the effect of shutting off the subgrid-scale bathymetry dominates over the change in ligand concentrations (Fig. 19). The difference in surface phosphate concentration between experiments BAT08 and LIG08 are similar to the differences with the higher ligand concentrations. Also with regard to the phosphate concentrations, the effect of shutting off the subgrid-scale bathymetry thus prevails over the effect of varying the ligand concentrations. Tagliabue et al. (2014a) even shut off the complete sediment source of iron and at the same time double and halve the ligand concentrations. Their results similarly show that on top of the changes in atmospheric $\mathrm{CO}_{2}$ concentration due to shutting off the sediment source of iron, ligand variations introduce additional changes of $10-25 \%$. Thus, the effect of shutting off the sediment release is also larger than the variation of the ligand concentrations in their results.

We scaled the sedimentary iron release with bottom water temperature to introduce temperature-dependent remineralization in sediments as it was already applied to remineralization in the water column in the previous model versions. Enzymatic reactions are directly temperature dependent (Arndt et al., 2013), so dissimilatory iron reduction in sediments should be temperature dependent as well. Although physiological adaptation of the benthic microbial community to low temperatures may compensate for some of the positive effect of temperature on remineralization rates (Arndt et al., 2013), lab experiments show that remineralization rates increase up to 7-fold when sediment is incubated at a temperature gradient (Arnosti et al., 1998; Sanz-Lázaro et al., 2011). The exact influence of temperature on remineralization in sediments is thus still unclear (Arndt et al., 2013). Our choice to include the temperature dependence on the sedimentary iron release is mainly motivated by too high simulated iron concentrations in the Southern Ocean without the temperature dependence. For comparison we optimized the ratio of iron released from the sediment and phosphorus in particulate matter that sinks into the sediment $\left(\mathrm{Fe}: \mathrm{P}_{\mathrm{sed}}=0.015 \mathrm{molFe}(\mathrm{molP})^{-1}\right)$ in a simulation without the temperature dependence of the sedimentary iron release to give the best possible agreement to observations and conducted a 1000 year test simulation. While the average observed iron concentrations south of $40^{\circ} \mathrm{S}$ are $0.52 \mathrm{nM}$, simulated concentrations are $0.67 \mathrm{nM}$ without and $0.53 \mathrm{nM}$ with the temperature dependence. Both simulations show a reasonable globally averaged vertical profile of dissolved iron while without the temperature dependence the profile appears to be closer to the observations because of generally higher concentrations (Fig. 20a). However, the difference between simulated and observed iron concentrations is smaller in the simulation with temperature dependence, particularly in the deep ocean below $3500 \mathrm{~m}$ but also from the surface down to $1500 \mathrm{~m}$ (Fig. 20b). Generally, the simulation without temperature dependence leads to lower iron concentrations in the tropical ocean, particular in the Indian Ocean 

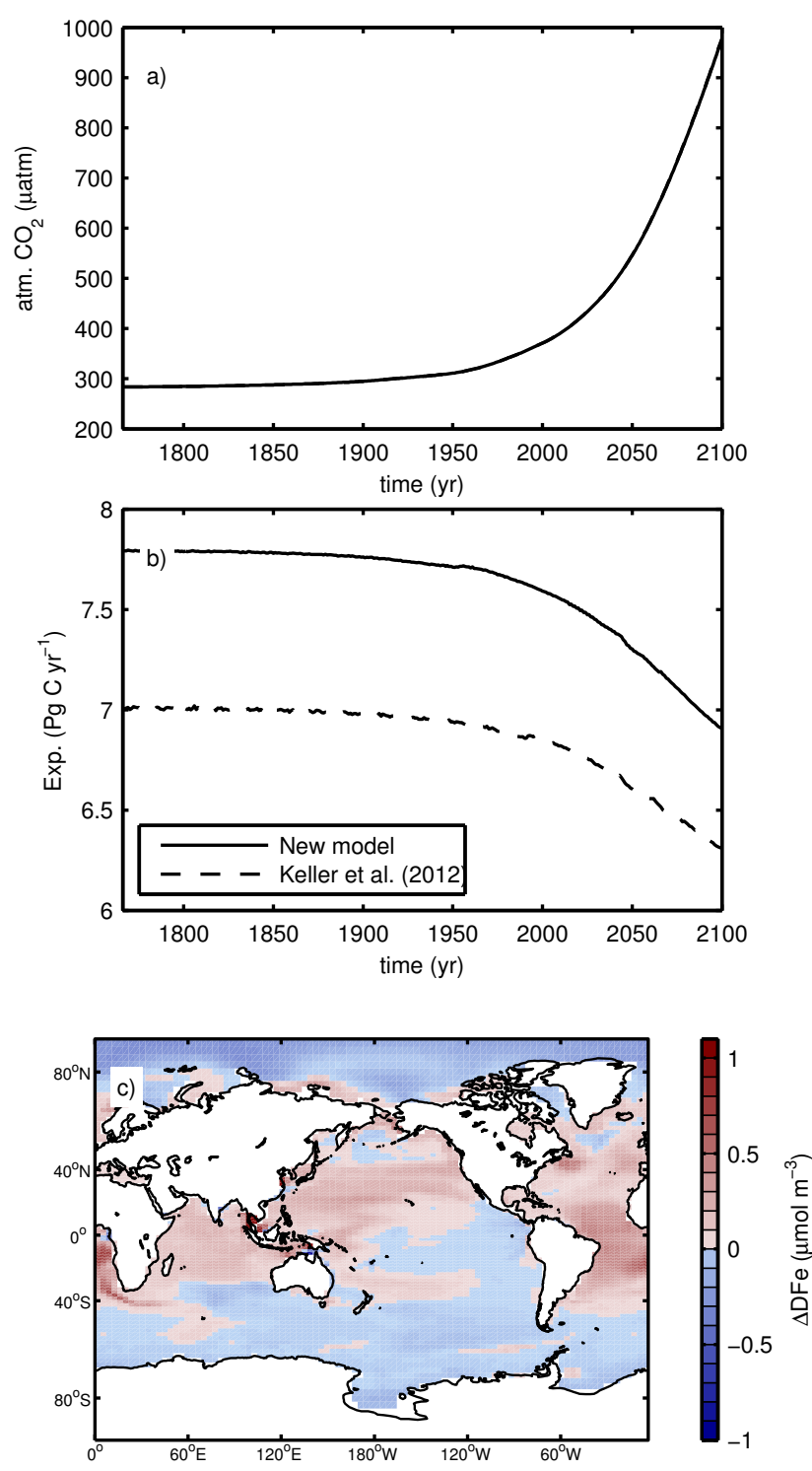

Figure 21. Results of the global warming scenario run following the high- $\mathrm{CO}_{2}$ emissions representative concentration pathway (RCP 8.5) scenario: (a) Annual average $\mathrm{CO}_{2}$ concentrations with the new model and with the model by Keller et al. (2012) (not distinguishable), (b) globally integrated export production at $80 \mathrm{~m}$ with the new model and with the model by Keller et al. (2012), (c) the difference in surface dissolved iron concentrations between the year 2100 and year 1765 .

and the western Pacific because of shallow water depths, and higher iron concentrations in the higher latitudes compared to the simulation without the temperature dependence. Thus, more phosphate is taken up in the higher latitudes and phosphate concentrations increase in the tropical regions and east of Australia due to an increase in iron limitation near Australia and in the tropical Pacific. The model without the temperature dependence and $\mathrm{Fe}: \mathrm{P}_{\text {sed }}=0.015 \mathrm{~mol} \mathrm{Fe}(\mathrm{molP})^{-1}$ can be seen as an alternative configuration. Although iron ob-
Table 3. Simulated fluxes in the iron cycle expressed in Gmol Fe $\mathrm{yr}^{-1}$ for the preindustrial model state at year 1765 and a future state at year 2100 . The difference of the fluxes is denoted by $\Delta$ Flux.

\begin{tabular}{llll}
\hline Flux name & 1765 & 2100 & $\Delta$ Flux \\
\hline Sediment release & 18.8 & 17.8 & -1 \\
Svavenging & 67.8 & 75.2 & +7.4 \\
Remineralization & 64.2 & 65.2 & +1 \\
Recycling & 28.6 & 26.7 & -1.9 \\
Uptake & 45.2 & 42.2 & -3 \\
Grazing/Lysis & 16.7 & 15.6 & -1.1 \\
\hline
\end{tabular}

servations are still scarce and associated with uncertainty as discussed before, because there is a better agreement with the observations with the temperature-dependent sedimentary iron release parameterization we made this formulation the standard one. However, more observations and experiments of the temperature dependence of benthic remineralization are needed to verify our assumption.

Finally, we performed a global warming scenario simulations with the old and the new model and analyzed the response of the ocean. The other components of the Earth system appear to be nearly not influenced by the inclusion of the dynamic iron cycle and the general response of the model to climate warming has already been analyzed in Eby et al. (2013), Zickfeld et al. (2013), and Keller et al. (2014). We ran both models from the 10000 year long spin-ups for an additional 200 years during which the atmospheric $\mathrm{CO}_{2}$ concentration was allowed to change. Then, we started the emissions driven climate change scenario in the year 1765 and ran the model to year 2100. The $\mathrm{CO}_{2}$ emissions follow historical observations to the year 2000 and then a high- $\mathrm{CO}_{2}$ emissions representative concentration pathway (RCP 8.5) scenario (Meinshausen et al., 2011). Changes in land use, volcanic and solar forcing, aerosols and other greenhouse gases are held constant in our simulations. The global warming scenario simulations with the old and new models do not differ much in terms of atmospheric $\mathrm{CO}_{2}$ concentrations (Fig. 21) as it is only $1.2 \mu$ atm lower in the year 2100 with the new model than with the old one. The inclusion of a dynamic iron cycle does thus not alter the oceanic $\mathrm{CO}_{2}$ exchange in our model during a climate change simulation on this timescale. However, export production is decreasing faster with the new model during the time from 1765 to 2100 . At the same time NPP decreased from 54.82 to $50.98 \mathrm{PgC} \mathrm{yr}^{-1}$ with the new

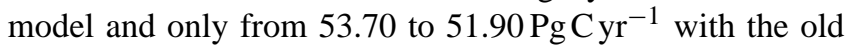
model. This stronger decrease is due to the increasing iron limitation in the iron limited regions such as the Southern Ocean, equatorial Pacific and North Pacific. The changes in iron limitation are caused by stronger stratification which increases iron concentrations at regions of high dust deposition but decreases iron in regions where supply from the deep ocean is dominant (Fig. 21c). 
During the climate warming simulation, we keep the atmospheric iron deposition constant but the sediment release of iron decreases from 18.8 to $17.8 \mathrm{GmolFe} \mathrm{yr}^{-1}$ (Table 3) due to the lower amount of organic matter reaching the sediment. In our model, the role of $\mathrm{O}_{2}$ on sediment release of iron is restricted to areas of $\mathrm{O}_{2}<5 \mathrm{mmol} \mathrm{m}^{-3}$ which, in our simulation, show a global decrease over the 21 st century under global warming as in Duteil and Oschlies (2011). While scavenging and remineralization increase by 7.4 and

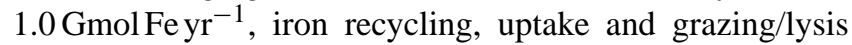
decrease during the simulations from 1765 to 2100 . This is caused by the higher stratification, leading to lower iron concentrations in the euphotic zone and higher concentrations below. Together this shows that the response of the dynamic iron cycle to the $\mathrm{CO}_{2}$ emission scenario has a limited impact on the atmospheric $\mathrm{CO}_{2}$ concentration on centennial timescales, but that the changes of iron concentration can be strong and possibly lead to changes in ocean biogeochemistry on longer timescales.

\section{Conclusions}

Including a dynamic iron cycle leads to a better agreement between observed and simulated iron and, to a minor extent, macronutrient concentrations than with the iron concentration mask used in the previous model (Keller et al., 2012). The iron cycle now also responds dynamically and interactively with the ocean biogeochemistry to possible perturbations. The improvement of the iron cycling model, when compared to other models such as the one by Misumi et al. (2013), is in part due to better constrained parameters, for example by Gledhill and Buck (2012). Since many fluxes and parameters of the iron cycle are still unconstrained and we find a strong sensitivity of the simulated iron concentrations to ligand concentrations, more observations are necessary, particular ones associated with scavenging since it is the largest flux in the iron cycle.

Many studies have focused on dust deposition as the dominant source of iron to the ocean (Parekh et al., 2008; Tagliabue et al., 2008; Oka et al., 2011; Nickelsen and Oschlies, 2015), while recently sediment release of iron has been suggested to also be highly important (Moore and Braucher, 2008; Tagliabue et al., 2009, 2014a). We add to these results with our experiments regarding the variable solubility of iron in dust, the temperature dependence of sedimentary iron release and the depth correction of iron release from the sediment. Although variable solubility of iron has a strong impact on the iron concentrations simulated by our model, its effect on macronutrient concentrations is small because it primarily alters iron concentrations in regions that are not iron limited. On the other hand, the subgrid-scale bathymetry for sedimentary iron release has a very strong impact on both iron concentrations and macronutrients because sediment release is the dominant source of iron in iron limited regions such as the Southern Ocean and eastern tropical Pacific in our model. The temperature dependence of the sedimentary iron release primarily leads to a better agreement between simulated and observed dissolved iron concentrations in the Southern Ocean. Changes in the sediment source can thus potentially drive strong changes in iron limitation at the surface and more observations on what controls sedimentary iron release are crucial.

The dynamic response of the iron cycle also allows us to investigate its response to climate change. A previous study found that physical changes in ocean circulation could influence iron supply in iron limited regions (Misumi et al., 2014). However, the largest external source of iron, the release of iron from the sediments, is constant in their model. Due to the strong control of iron released from the sediments on surface iron limitation shown earlier, the response of the sedimentary iron release to climate change could contribute largely to changes of iron concentration and primary production. Sediment release of iron depends on organic matter reaching the sediment, temperature and bottom water oxygen concentrations in our model, all of which change during climate change. Particularly changes in oxygen concentrations could influence iron release from the sediment and could, in turn, also be influenced by iron limitation at the ocean surface. Lower iron limitation could lead to higher export of organic matter and oxygen consumption during respiration. The possible interaction between oxygen and iron concentrations and parameterizations of iron release from the sediment are thus worth to be investigated further.

\section{Model code availability}

The University of Victoria Earth System Climate Model version 2.9 (2009) together with a readme file is available at http://www.climate.uvic.ca/model/. The complete files of the model code of the model version used in this paper that are different to files at http://www.climate.uvic.ca/model/ are available in the Supplement together with additional forcing files. Please see the readme file in the Supplement for further instructions on how to use the code. In addition, the model output of the last 1000 years which is used to create the plots and restart files after 9000 and 10000 years of the 10000 year spin-up are provided at https://thredds.geomar. de/thredds/fileServer/peerReviewData/nickelsen-et-al_ gmd_2014/Nickelsen-et-al_GMD_2014_submitted.zip.

\section{The Supplement related to this article is available online at doi:10.5194/gmd-8-1357-2015-supplement.}

Acknowledgements. We acknowledge financial support from the Deutsche Forschungsgemeinschaft (SFB 754). We thank Michael Eby (University of Victoria, Victoria, Canada) for maintaining the code of the UVic model, Natalie Mahowald (Cornell 
University, Ithaca, USA) for sharing the dust deposition estimates and Heiner Dietze (GEOMAR, Kiel, Germany) for helpful discussions, advice and technical support.

Edited by: A. Ridgwell

\section{References}

Arndt, S., Jørgensen, B., LaRowe, D., Middelburg, J., Pancost, R., and Regnier, P.: Quantifying the degradation of organic matter in marine sediments: a review and synthesis, Earth-Sci. Rev., 123, 53-86, 2013.

Arnosti, C., Jørgensen, B., Sagemann, J., and Thamdrup, B.: Temperature dependence of microbial degradation of organic matter in marine sediments: polysaccharide hydrolysis, oxygen consumption, and sulfate reduction, Mar. Ecol.-Prog. Ser., 165, 5970, 1998.

Aumont, O. and Bopp, L.: Globalizing results from ocean in situ iron fertilization studies, Global Biogeochem. Cy., 20, 1-15, doi:10.1029/2005GB002591, 2006.

Baker, A. R. and Croot, P.: Atmospheric and marine controls on aerosol iron solubility in seawater, Mar. Chem., 120, 4-13, doi:10.1016/j.marchem.2008.09.003, 2010.

Behrenfeld, M. J. and Falkowski, P.: Photosynthetic rates derived from satellite-based chlorophyll concentration, Limnol. Oceanogr., 42, 1-20, 1997.

Boyd, P. W. and Ellwood, M. J.: The biogeochemical cycle of iron in the ocean, Nat. Geosci., 3, 675-682, doi:10.1038/ngeo964, 2010.

Buitenhuis, E. T., Hashioka, T., and Quéré, C. L.: Combined constraints on global ocean primary production using observations and models, Global Biogeochem. Cy., 2012, doi:10.1002/gbc.20074, 2013.

Cox, P. M.: Description of the TRIFFID dynamic global vegetation model, Technical Report Technical Note, HCTN24, 1-16, available at: http://www.metoffice.gov.uk/media/pdf/9/h/HCTN_ 24.pdf (last access: 15 October 2014), 2001.

Dale, A. W., Nickelsen, L., Scholz, F., Hensen, C., Oschlies, A., and Wallmann, K.: A revised global estimate of dissolved iron fluxes from marine sediments, Global Biogeochem. Cycles, accepted, doi:10.1002/2014GB005017, 2015.

Dietze, H. and Loeptien, U.: Revisiting "nutrient trapping" in global coupled biogeochemical ocean circulation models, Global Biogeochem. Cy., 27, 265-284, doi:10.1002/gbc.20029, 2013.

Duteil, O. and Oschlies, A.: Sensitivity of simulated extent and future evolution of marine suboxia to mixing intensity, Geophys. Res. Lett., 38, L06607, doi:10.1029/2011GL046877, 2011.

Eby, M., Zickfeld, K., Montenegro, A., Archer, D., Meissner, K. J., and Weaver, A. J.: Lifetime of anthropogenic climate change: millennial time scales of potential $\mathrm{CO}_{2}$ and surface temperature perturbations, J. Climate, 22, 2501-2511, doi:10.1175/2008JCLI2554.1, 2009.

Eby, M., Weaver, A. J., Alexander, K., Zickfeld, K., Abe-Ouchi, A., Cimatoribus, A. A., Crespin, E., Drijfhout, S. S., Edwards, N. R., Eliseev, A. V., Feulner, G., Fichefet, T., Forest, C. E., Goosse, H., Holden, P. B., Joos, F., Kawamiya, M., Kicklighter, D., Kienert, H., Matsumoto, K., Mokhov, I. I., Monier, E., Olsen, S. M., Pedersen, J. O. P., Perrette, M., Philippon-Berthier, G., Ridgwell, A., Schlosser, A., Schneider von Deimling, T., Shaffer, G., Smith, R.
S., Spahni, R., Sokolov, A. P., Steinacher, M., Tachiiri, K., Tokos, K., Yoshimori, M., Zeng, N., and Zhao, F.: Historical and idealized climate model experiments: an intercomparison of Earth system models of intermediate complexity, Clim. Past, 9, 11111140, doi:10.5194/cp-9-1111-2013, 2013.

Elrod, V. A., Berelson, W. M., Coale, K. H., and Johnson, K.: The flux of iron from continental shelf sediments: a missing source for global budgets, Geophys. Res. Lett., 31, 2-5, doi:10.1029/2004GL020216, 2004.

Eppley, R.: Temperature and phytoplankton growth in the sea, Fish. Bull., 70, 1063-1085, 1972.

Fernandez, C., Farías, L., and Ulloa, O.: Nitrogen fixation in denitrified marine waters, PloS one, 6, e20539, doi:10.1371/journal.pone.0020539, 2011.

Galbraith, E. D., Gnanadesikan, A., Dunne, J. P., and Hiscock, M. R.: Regional impacts of iron-light colimitation in a global biogeochemical model, Biogeosciences, 7, 1043-1064, doi:10.5194/bg-7-1043-2010, 2010.

Garcia, H. E., Locarnini, R. A., Boyer, T. P., Antonov, J. I., Baranova, O. K., Zweng, M. M., and Johnson, D. R.: World Ocean Atlas 2009, Volume 3: Dissolved Oxygen, Apparent Oxygen Utilization, and Oxygen Saturation, edited by: Levitus, S., NOAA Atlas NESDIS 70, US Government Printing Office, Washington, D.C., p. 344, 2010a.

Garcia, H. E., Locarnini, R. A., Boyer, T. P., Antonov, J. I., Zweng, M. M., Baranova, O. K., and Johnson, D. R.: World Ocean Atlas 2009, Volume 4: Nutrients (phosphate, nitrate, silicate), edited by: Levitus, S., NOAA Atlas NESDIS 71, US Government Printing Office, Washington, D.C., p. 398, 2010 b.

Geider, R. J., MacIntyre, H. L., and Kana, T. M.: Dynamic model of phytoplankton growth and acclimation: responses of the balanced growth rate and the chlorophyll a: carbon ratio to light, nutrient-limitation and temperature, Mar. Ecol.-Prog. Ser., 148, 187-200, doi:10.3354/meps148187, 1997.

Gent, P. and McWilliams, J.: Isopycnal mixing in ocean circulation models, J. Phys. Oceanogr., 20, 150-155, doi:10.1175/15200485(1990)020<0150:IMIOCM>2.0.CO;2, 1990.

Getzlaff, J. and Dietze, H.: Effects of increased isopycnal diffusivity mimicking the unresolved equatorial intermediate current system in an earth system climate model, Geophys. Res. Lett., 40, 2166 2170, doi:10.1002/grl.50419, 2013.

Gledhill, M. and Buck, K.: The organic complexation of iron in the marine environment: a review, Frontiers in Microbiology, 3, 117, doi:10.3389/fmicb.2012.00069, 2012.

Honeyman, B. D., Balistrieri, L., and Murray, J.: Oceanic trace metal scavenging: the importance of particle concentration, Deep-Sea Res., 35, 227-246, doi:10.1016/0198-0149(88)900386, 1988.

Hopkinson, B. and Barbeau, K.: Organic and redox speciation of iron in the eastern tropical North Pacific suboxic zone, Mar. Chem., 106, 2-17, doi:10.1016/j.marchem.2006.02.008, 2007.

Hopkinson, B., Mitchell, B., Reynolds, R., Wang, H., Selph, K., Measures, C. I., Hewes, C., Holm-Hansen, O., and Barbeau, K.: Iron limitation across chlorophyll gradients in the southern Drake Passage: phytoplankton responses to iron addition and photosynthetic indicators of iron stress, Limnol. Oceanogr., 52, 2540 2554, 2007. 
Johnson, K., Gordon, R., and Coale, K. H.: What controls dissolved iron concentrations in the world ocean?, Mar. Chem., 57, 181186, doi:10.1016/S0304-4203(97)00047-9, 1997.

Keller, D. P., Oschlies, A., and Eby, M.: A new marine ecosystem model for the University of Victoria Earth System Climate Model, Geosci. Model Dev., 5, 1195-1220, doi:10.5194/gmd-51195-2012, 2012.

Keller, D. P., Feng, E. Y., and Oschlies, A.: Potential climate engineering effectiveness and side effects during a high carbon dioxide-emission scenario, Nature Communications, 5, 3304, doi:10.1038/ncomms4304, 2014.

Key, R. M., Kozyr, A., Sabine, C. L., Lee, K., Wanninkhof, R., Bullister, J. L., Feely, R. A., Millero, F. J., Mordy, C., and Peng, T.-H.: A global ocean carbon climatology: results from Global Data Analysis Project (GLODAP), Global Biogeochem. Cy., 18, GB4031, doi:10.1029/2004GB002247, 2004.

Landolfi, A., Dietze, H., Koeve, W., and Oschlies, A.: Overlooked runaway feedback in the marine nitrogen cycle: the vicious cycle, Biogeosciences, 10, 1351-1363, doi:10.5194/bg-10-1351-2013, 2013.

Large, W. G., Danabasoglu, G., McWilliams, J. C., Gent, P. R., and Bryan, F. O.: Equatorial circulation of a global ocean climate model with anisotropic horizontal viscosity, J. Phys. Oceanogr., 13, 518-536, doi:10.1175/15200485(2001)031\%3C0518:ECOAGO\%3E2.0.CO;2, 2001.

Luo, C., Mahowald, N. M., Bond, T., Chuang, P. Y., Artaxo, P., Siefert, R. L., Chen, Y., and Schauer, J.: Combustion iron distribution and deposition, Global Biogeochem. Cy., 22, 1-17, doi:10.1029/2007GB002964, 2008.

Mahowald, N. M., Muhs, D. R., Levis, S., Rasch, P. J., Yoshioka, M., Zender, C. S., and Luo, C.: Change in atmospheric mineral aerosols in response to climate: last glacial period, preindustrial, modern, and doubled carbon dioxide climates, J. Geophys. Res., 111, D10202, doi:10.1029/2005JD006653, 2006.

Mahowald, N. M., Engelstaedter, S., Luo, C., Sealy, A., Artaxo, P., Benitez-Nelson, C., Bonnet, S., Chen, Y., Chuang, P. Y., Cohen, D. D., Dulac, F., Herut, B., Johansen, A. M., Kubilay, N., Losno, R., Maenhaut, W., Paytan, A., Prospero, J. M., Shank, L. M., and Siefert, R. L.: Atmospheric iron deposition: global distribution, variability, and human perturbations, Annu. Rev. Marine Sci., 1, 245-278, doi:10.1146/annurev.marine.010908.163727, 2009.

Mahowald, N. M., Kloster, S., Engelstaedter, S., Moore, J. K., Mukhopadhyay, S., McConnell, J. R., Albani, S., Doney, S. C., Bhattacharya, A., Curran, M. A. J., Flanner, M. G., Hoffman, F. M., Lawrence, D. M., Lindsay, K., Mayewski, P. A., Neff, J., Rothenberg, D., Thomas, E., Thornton, P. E., and Zender, C. S.: Observed 20th century desert dust variability: impact on climate and biogeochemistry, Atmos. Chem. Phys., 10, 10875-10893, doi:10.5194/acp-10-10875-2010, 2010.

Martinez-Garcia, A., Sigman, D. M., Ren, H., Anderson, R. F., Straub, M., Hodell, D. A., Jaccard, S. L., Eglinton, T. I., and Haug, G. H.: Iron fertilization of the subantarctic ocean during the last ice age, Science, 343, 1347-1350, doi:10.1126/science.1246848, 2014.

Meinshausen, M., Smith, S. J., Calvin, K., Daniel, J. S., Kainuma, M. L. T., Lamarque, J.-F., Matsumoto, K., Montzka, S. A., Raper, S. C. B., Riahi, K., Thomson, A., Velders, G. J. M., and Vuuren, D. P.: The RCP greenhouse gas concentrations and their extensions from 1765 to 2300 , Clim. Change, 109, 213-241, doi:10.1007/s10584-011-0156-z, 2011.

Meissner, K. J., Weaver, A. J., Matthews, H. D., and Cox, P. M.: The role of land surface dynamics in glacial inception: a study with the UVic Earth System Model, Clim. Dynam., 21, 515-537, doi:10.1007/s00382-003-0352-2, 2003.

Mills, M., Ridame, C., Davey, M., Roche, J. L., and Geider, R. J.: Iron and phosphorus co-limit nitrogen fixation in the eastern tropical North Atlantic, Nature, 429, 292-294, 2004.

Misumi, K., Lindsay, K., Moore, J. K., Doney, S. C., Tsumune, D., and Yoshida, Y.: Humic substances may control dissolved iron distributions in the global ocean: implications from numerical simulations, Global Biogeochem. Cy., 27, 450-462, doi:10.1002/gbc.20039, 2013.

Misumi, K., Lindsay, K., Moore, J. K., Doney, S. C., Bryan, F. O., Tsumune, D., and Yoshida, Y.: The iron budget in ocean surface waters in the 20th and 21st centuries: projections by the Community Earth System Model version 1, Biogeosciences, 11, 33-55, doi:10.5194/bg-11-33-2014, 2014.

Moffett, J. W., Goepfert, T. J., and Naqvi, S. W. A.: Reduced iron associated with secondary nitrite maxima in the Arabian Sea, Deep-Sea Res. Pt. I, 54, 1341-1349, doi:10.1016/j.dsr.2007.04.004, 2007.

Moore, J. K. and Braucher, O.: Sedimentary and mineral dust sources of dissolved iron to the world ocean, Biogeosciences, 5, 631-656, doi:10.5194/bg-5-631-2008, 2008.

Moore, J. K. and Doney, S. C.: Iron availability limits the ocean nitrogen inventory stabilizing feedbacks between marine denitrification and nitrogen fixation, Global Biogeochem. Cy., 21, 1-12, doi:10.1029/2006GB002762, 2007.

Najjar, R., Sarmiento, J. L., and Toggweiler, J. R.: Downward transport and fate of organic matter in the ocean: simulations with a general circulation mdoel, Global Biogeochem. Cy., 6, 45-76, doi:10.1029/91GB02718, 1992.

Nickelsen, L. and Oschlies, A.: Enhanced sensitivity of oceanic $\mathrm{CO}_{2}$ uptake to dust deposition by iron-light colimitation, Geophys. Res. Lett., 42, 492-499, doi:10.1002/2014GL062969, 2015.

Noffke, A., Hensen, C., Sommer, S., Scholz, F., Bohlen, L., Mosch, T., Graco, M., and Wallmann, K.: Benthic iron and phosphorus fluxes across the Peruvian oxygen minimum zone, Limnol. Oceanogr., 57, 851-867, 2012.

Oka, A., Abe-Ouchi, A., Chikamoto, M. O., and Ide, T.: Mechanisms controlling export production at the LGM: effects of changes in oceanic physical fields and atmospheric dust deposition, Global Biogeochem. Cy., 25, 1-12, doi:10.1029/2009GB003628, 2011.

Oschlies, A., and Garçon, V.: An eddy-permitting coupled physicalbiological model of the North Atlantic: 1 . Sensitivity to advection numerics and mixed layer physics, Global Biogeochem. Cy., 13, 135-160, doi:10.1029/98GB02811, 1999.

Parekh, P., Follows, M. J., and Boyle, E. A.: Modeling the global ocean iron cycle, Global Biogeochem. Cy., 18, GB1002, doi:10.1029/2003GB002061, 2004.

Parekh, P., Follows, M. J., and Boyle, E. A.: Decoupling of iron and phosphate in the global ocean, Global Biogeochem. Cy., 19, GB2020, doi:10.1029/2004GB002280, 2005.

Parekh, P., Joos, F., and Müller, S. A.: A modeling assessment of the interplay between aeolian iron fluxes and iron- 
binding ligands in controlling carbon dioxide fluctuations during Antarctic warm events, Paleoceanography, 23, 1-14, doi:10.1029/2007PA001531, 2008.

Price, N.: The elemental stoichiometry and composition of an ironlimited diatom, Limnol. Oceanogr., 50, 1159-1171, 2005.

Price, N., Ahner, B., and Morel, F.: The equatorial Pacific Ocean: grazer-controlled phytoplankton populations in an iron-limited ecosystem, Limnol. Oceanogr., 39, 520-534, 1994.

Rijkenberg, M. J. A., Steigenberger, S., Powell, C. F., van Haren, H., Patey, M. D., Baker, A. R., and Achterberg, E. P.: Fluxes and distribution of dissolved iron in the eastern (sub-) tropical North Atlantic Ocean, Global Biogeochem. Cy., 26, GB3004, doi:10.1029/2011GB004264, 2012.

Sabine, C. L., Feely, R., Gruber, N., Key, R. M., Lee, K., Bullister, J. L., Wanninkhof, R., Wong, C. S., Wallace, D. W. R., Tilbrook, B., Millero, F. J., Peng, T.-H., Kozyr, A., Ono, T., and Rios, A. F.: The oceanic sink for anthropogenic $\mathrm{CO}_{2}$, Science, 305, 367-371, 2004.

Sanz-Lázaro, C., Valdemarsen, T., Marín, A., and Holmer, M.: Effect of temperature on biogeochemistry of marine organicenriched systems: implications in a global warming scenario, Ecol. Appl., 21, 2664-2677, 2011.

Schmittner, A., Oschlies, A., Giraud, X., Eby, M., and Simmons, H. L.: A global model of the marine ecosystem for longterm simulations: sensitivity to ocean mixing, buoyancy forcing, particle sinking, and dissolved organic matter cycling, Global Biogeochem. Cy., 19, 1-17, doi:10.1029/2004GB002283, 2005.

Schmittner, A., Oschlies, A., Matthews, H. D., and Galbraith, E. D.: Future changes in climate, ocean circulation, ecosystems, and biogeochemical cycling simulated for a business-as-usual $\mathrm{CO}_{2}$ emission scenario until year $4000 \mathrm{AD}$, Global Biogeochem. Cy., 22, 1-21, doi:10.1029/2007GB002953, 2008.

Schmittner, A., Oschlies, A., Matthews, H. D., and Galbraith, E. D.: Correction to "Future changes in climate, ocean circulation, ecosystems, and biogeochemical cycling simulated for a business-as-usual $\mathrm{CO}_{2}$ emission scenario until year 4000 AD", Global Biogeochem. Cy., 23, 1-1, doi:10.1029/2009GB003577, 2009.

Severmann, S., McManus, J., Berelson, W. M., and Hammond, D. E.: The continental shelf benthic iron flux and its isotope composition, Geochim. Cosmochim. Ac., 74, 3984-4004, doi:10.1016/j.gca.2010.04.022, 2010.

Siedlecki, S., Mahadevan, A., and Archer, D.: Mechanism for export of sediment-derived iron in an upwelling regime, Geophys. Res. Lett., 39, 2-7, doi:10.1029/2011GL050366, 2012.

Simmons, H. L., Jayne, S. R., Laurent, L. C. S., and Weaver, A. J.: Tidally driven mixing in a numerical model of the ocean general circulation, Ocean Model., 6, 245-263, doi:10.1016/S14635003(03)00011-8, 2004

Somes, C. J., Schmittner, A., and Altabet, M. A.: Nitrogen isotope simulations show the importance of atmospheric iron deposition for nitrogen fixation across the Pacific Ocean, Geophys. Res. Lett., 37, 1-6, doi:10.1029/2010GL044537, 2010.

Somes, C. J., Oschlies, A., and Schmittner, A.: Isotopic constraints on the pre-industrial oceanic nitrogen budget, Biogeosciences, 10, 5889-5910, doi:10.5194/bg-10-5889-2013, 2013.

Tagliabue, A. and Völker, C.: Towards accounting for dissolved iron speciation in global ocean models, Biogeosciences, 8, 30253039, doi:10.5194/bg-8-3025-2011, 2011.
Tagliabue, A., Bopp, L., and Aumont, O.: Ocean biogeochemistry exhibits contrasting responses to a large scale reduction in dust deposition, Biogeosciences, 5, 11-24, doi:10.5194/bg-5-112008, 2008.

Tagliabue, A., Bopp, L., and Aumont, O.: Evaluating the importance of atmospheric and sedimentary iron sources to Southern Ocean biogeochemistry, Geophys. Res. Lett., 36, 1-5, doi:10.1029/2009GL038914, 2009.

Tagliabue, A., Mtshali, T., Aumont, O., Bowie, A. R., Klunder, M. B., Roychoudhury, A. N., and Swart, S.: A global compilation of dissolved iron measurements: focus on distributions and processes in the Southern Ocean, Biogeosciences, 9, 2333-2349, doi:10.5194/bg-9-2333-2012, 2012.

Tagliabue, A., Aumont, O., and Bopp, L.: The impact of different external sources of iron on the global carbon cycle, Geophys. Res. Lett., 41, 920-926, doi:10.1002/2013GL059059, 2014a.

Tagliabue, A., Sallée, J., Bowie, A., Lévy, M., Swart, S., and Boyd, P. W.: Surface-water iron supplies in the Southern Ocean sustained by deep winter mixing, Nat. Geosci., 1-7, doi:10.1038/NGEO2101, 2014b.

Timmermans, K. R., Wagt, B. V. D., and de Baar, H. J. W.: Growth rates, half saturation constants, and silicate, nitrate, and phosphate depletion in relation to iron availability of four large openocean diatoms from the Southern Ocean, Limnol. Oceanogr., 49, 2141-2151, doi:10.4319/lo.2004.49.6.2141, 2004.

US Dept. of Commerce, National Oceanic and Atmospheric Administration, and National Geophysical Data Center: 2-minute Gridded Global Relief Data (ETOPO2v2), available at: http: //www.ngdc.noaa.gov/mgg/global/etopo2.html (last access: 15 October 2014), 2006.

Völker, C. and Tagliabue, A.: Modeling organic iron-binding ligands in a three-dimensional biogeochemical ocean model, Mar Chem., 173, 67-77, doi:10.1016/j.marchem.2014.11.008, 2015.

Wallmann, K.: Phosphorus imbalance in the global ocean?, Global Biogeochem. Cy., 24, 1-12, doi:10.1029/2009GB003643, 2010.

Weaver, A. J., Eby, M., Wiebe, E. C., Bitz, C. M., Duffy, P. B., Ewen, T. L., Fanning, A. F., Holland, M. M., MacFayden, A., Matthews, H. D., Meissner, K. J., Saenko, O., Schmittner, A., Wang, H., and Yoshimori, M.: The UVic Earth System Climate Model: model description, climatology, and applications to past, present and future climates, Atmos.-Ocean, 39, 361-428, doi:10.1080/07055900.2001.9649686, 2001.

Westberry, T., Behrenfeld, M. J., Siegel, D. A., and Boss, E.: Carbon-based primary productivity modeling with vertically resolved photoacclimation, Global Biogeochem. Cy., 22, GB2024, doi:10.1029/2007GB003078, 2008.

Zickfeld, K., Eby, M., Weaver, A. J., Alexander, K., Crespin, E., Edwards, N. R., Eliseev, A. V., Feulner, G., Fichefet, T., Forest, C. E., Friedlingstein, P., Goosse, H., Holden, P. B., Joos, F., Kawamiya, M., Kicklighter, D., Kienert, H., Matsumoto, K., Mokhov, I. I., Monier, E., Olsen, S. M., Pedersen, J. O. P., Perrette, M., Philippon-Berthier, G., Ridgwell, A., Schlosser, A., Schneider Von Deimling, T., Shaffer, G., Sokolov, A., Spahni, R., Steinacher, M., Tachiiri, K., Tokos, K. S., Yoshimori, M., Zeng, N., and Zhao, F.: Long-term climate change commitment and reversibility: an EMIC intercomparison, J. Climate, 26, 5782-5809, doi:10.1175/JCLI-D-12-00584.1, 2013. 